\title{
Guidelines
}

\section{Long-Term Mechanical Ventilation: Recommendations of the Swiss Society of Pulmonology}

\author{
Jean-Paul Janssens ${ }^{\text {a }}$ Franz Michel ${ }^{b}$ Esther Irene Schwarz ${ }^{c}$ Maura Prella ${ }^{d}$ \\ Konrad Bloch ${ }^{c}$ Dan Adler ${ }^{a}$ Anne-Kathrin Brille Aurore Geenens ${ }^{f}$ \\ Werner Karrer ${ }^{g}$ Adam Ogna ${ }^{\mathrm{h}}$ Sebastien Ott ${ }^{\mathrm{i}, j}$ Jochen Rüdiger ${ }^{\mathrm{k}}$ \\ Otto D. Schoch' Markus Soler ${ }^{j} \quad$ Werner Strobel $^{m}$ Christophe Uldry ${ }^{n}$ \\ Grégoire Gex ${ }^{a}$ o on behalf of the Special Interest Group on Ventilation and \\ Oxygen Therapy of the Swiss Society of Pneumology
}

\begin{abstract}
a Division of Pulmonary Diseases, Geneva University Hospitals, Geneva, Switzerland; 'b Klinik für Neurorehabilitation und Paraplegiologie, Basel, Switzerland; ' Department of Pulmonology and Sleep Disorders Centre, University Hospital of Zurich, Zurich, Switzerland; d Division of Pulmonary Diseases, Lausanne University Hospital (CHUV),

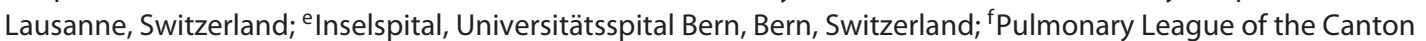

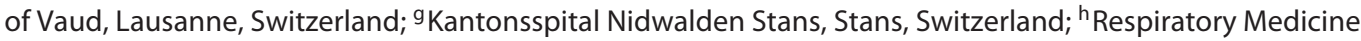
Service, Locarno Regional Hospital, Locarno, Switzerland; 'Universitätsklinik für Pneumologie, Universitätsspital (Inselspital) und Universität, Bern, Switzerland; 'Division of Pulmonary Diseases, St. Claraspital, Basel, Switzerland; ${ }^{k}$ Division of Pulmonary and Sleep Medicine, Medizin Stollturm, Münchenstein, Switzerland; 'Division of Pulmonary

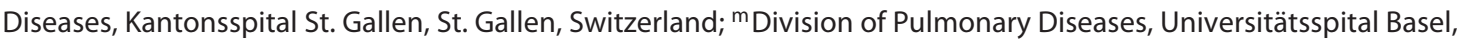
Basel, Switzerland; ${ }^{n}$ Division of Pulmonary Diseases and Pulmonary Rehabilitation Center, Rolle Hospital, Rolle, Switzerland; ${ }^{\circ}$ Division of Pulmonary Diseases, Hôpital du Valais, Sion, Switzerland
\end{abstract}

\section{Keywords}

Non-invasive ventilation · Invasive ventilation · Chronic hypercapnic respiratory failure $\cdot$ Sleep-related breathing disorders $\cdot$ Home mechanical ventilation

\footnotetext{
Abstract

Long-term mechanical ventilation is a well-established treatment for chronic hypercapnic respiratory failure (CHRF). It is aimed at improving CHRF-related symptoms, health-related quality of life, survival, and decreasing hospital admissions. In Switzerland, long-term mechanical ventilation has been increasingly used since the 1980s in hospital and home care
}

settings. Over the years, its application has considerably expanded with accumulating evidence of beneficial effects in a broad range of conditions associated with CHRF. Most frequent indications for long-term mechanical ventilation are chronic obstructive pulmonary disease, obesity hypoventilation syndrome, neuromuscular and chest wall diseases. In the current consensus document, the Special Interest Group of the Swiss Society of Pulmonology reviews the most recent scientific literature on long-term mechanical ventilation and provides recommendations adapted to the particular setting of the Swiss healthcare system with a focus on the practice of non-invasive and invasive home ventilation in adults.

(c) 2020 S. Karger AG, Basel karger@karger.com www.karger.com/res

(C) 2020 S. Karger AG, Base

Karger!
Jean-Paul Janssens

Division of Pulmonology, Department of Medicine Geneva University Hospitals

CH-1205 Geneva (Switzerland)

jean-paul.janssens@hcuge.ch 


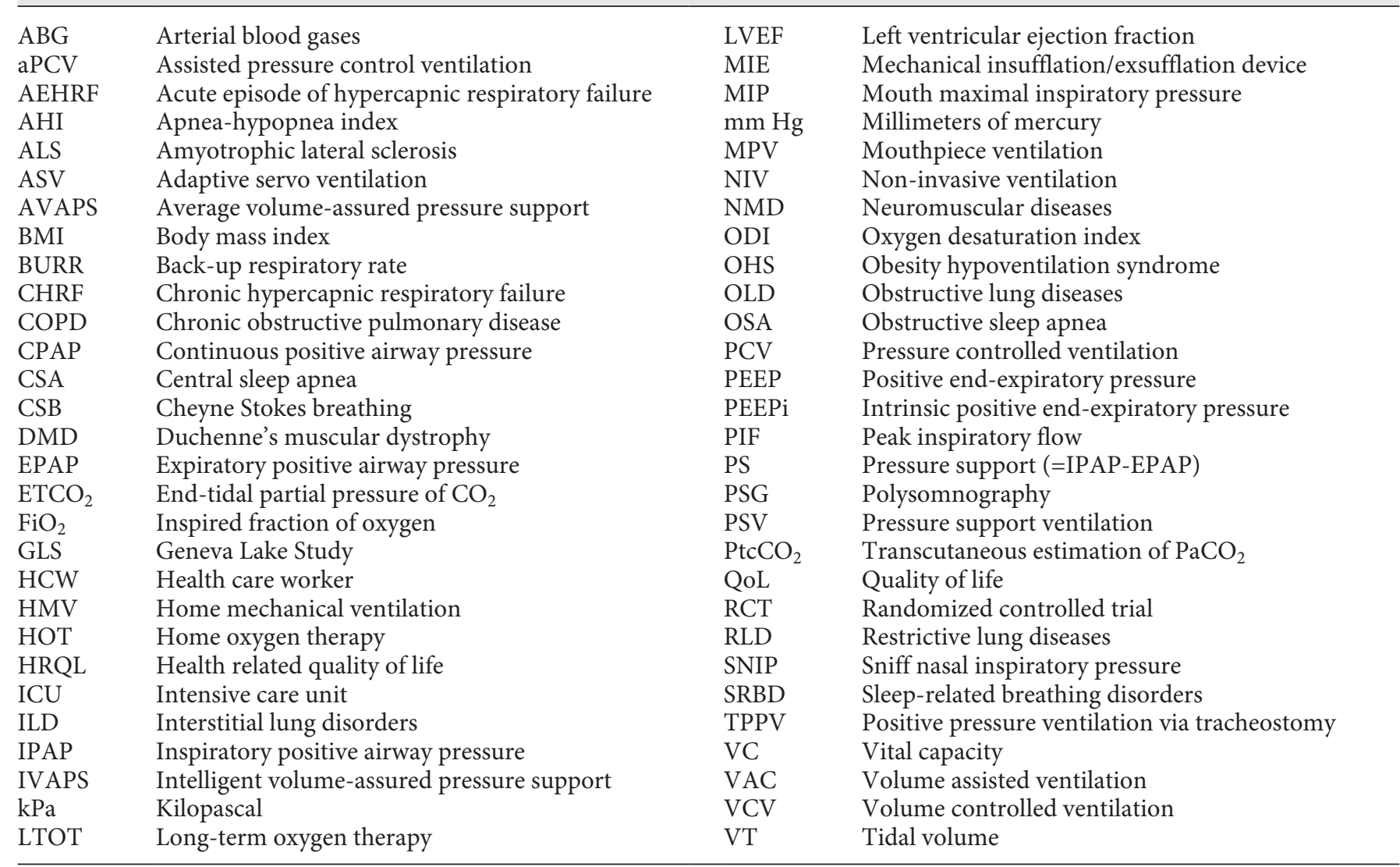




\section{Contents}

\section{Introduction}

1.1. Methodology

1.2. Indications for Long-term Non-Invasive Ventilation

1.3. General Comments and Caveats

1.4. Choice of Ventilators and Ventilator Modes

1.5. Comments on Specific Ventilator Settings

1.6. Humidifiers

1.7. Tubings, Circuits and Filters

1.8. Interfaces

1.9. Where, How and by Whom Should Home NIV be Implemented?

1.10. Tools for Measuring Arterial Blood Gases

1.11. Frequent Side Effects of Mechanical Ventilation and Their Management

2. Obstructive Lung Diseases (OLD)

2.1. General Comments

2.2. Ventilator Settings

2.3. Obstructive Lung Diseases Other Than COPD

\section{Obesity-Hypoventilation Syndrome}

3.1. General Comments

3.2. Ventilator Settings and Persistent Hypoxemia

\section{Restrictive Lung Diseases (RLD) Other Than Obesity-Hypoventilation and Neuro-Muscular Diseases \\ 4.1. Ventilator Settings}

\section{Neuromuscular diseases}

5.1. General Comments and Caveats

5.2. Follow-Up before Implementing NIV

5.3. Ventilator Settings

5.4. Interfaces in NMD

5.5. Mechanical Insufflation/Exsufflation (MIE) in NMD

\section{Sleep-Related Breathing Disorders}

6.1. General Comments

6.2. Indications

\section{Special Situations}

7.1. The Highly Dependent Patient

7.2. NIV and Rehabilitation

7.3. NIV and Palliative Care

7.4. Invasive Home Mechanical Ventilation

7.4.1. Invasive Ventilation in Switzerland and other Countries

7.4.2. Conditions in Which TPPV Is Used

7.4.3. Consequences of TPPV

7.4.4. Practical Aspects

7.4.5. Special Considerations in Spinal Cord Injuries

7.4.6. Management of Airway Secretions and Use of Mechanical Insufflation/Exsufflation

\section{Transition from Acute Care to Home Care}

\section{Acknowledgments}

Long-Term Mechanical Ventilation: Recommendations of the SSP
Respiration 2020;99:867-902 DOI: $10.1159 / 000510086$ 


\section{Introduction}

Home non-invasive positive pressure ventilation (NIV) appeared in Switzerland in the mid-80s, as in most neighboring countries, shortly after the publication by Sullivan et al. [1] of the successful treatment of obstructive sleep apnea (OSA) by continuous positive airway pressure via a nasal mask (CPAP). In 1990, 24 patients were ventilated non-invasively in Switzerland [2]. Although there are no official national statistics, a reasonable estimation of the trend in prevalence of home NIV can be derived from 2 surveys performed in the Cantons of Geneva and Vaud (Geneva Lake Study; GLS) [3, 4]. Between 2000 and 2018, NIV users increased from $15 / 10^{5}$ to $38 / 10^{5}$ inhabitants. To put these figures in perspective, use of CPAP in the same area $(\approx 20,000$ patients treated $)$ is presently 40 times higher $\left(1,552 / 10^{5}\right.$ inhabitants) [5]. Conversely, the number of patients on invasive ventilation via tracheostomy remains marginal. These figures are close to those reported by European countries with a national registry: $47 / 10^{5}$ inhabitants in Norway (September 2019, Norwegian National registry for long-term ventilation), 33/10 $0^{5}$ inhabitants in Sweden (2018, Swedevox), and $39.5 / 10^{5}$ inhabitants in Finland [6].

\subsection{Methodology}

The Swiss Society of Pulmonology (SSP) and the Swiss Society of Pediatric Pulmonology have previously published recommendations on home mechanical ventilation (HMV; 1996, 2006, 2010) [7-9]. This narrative review includes the most recent recommendations of our group based on an extensive review of the medical literature through PubMed over the past 10 years, of other national guidelines [10-15], and of the specifics of care for long-term HMV in Switzerland. The final text was discussed thoroughly among the members of the Special Interest Group on HMV (SIG) to reach a consensus.

This text focuses on HMV provided at home or in long-term care institutions and will cover indications, modalities and follow-up of patients on HMV. We will also comment on the use of mechanical insufflation/exsufflation (MIE) devices, and their indication. This document does not cover NIV in the acute care setting (emergency ward, ICU, acute-care hospital wards) or the pediatric population.

\subsection{Indications for Long-Term Non-Invasive \\ Ventilation}

Indications for long-term NIV, which have evolved over the past 30 years, are summarized in Figure 1 and
Table 1 [16]. The obesity-hypoventilation syndrome (OHS), chronic obstructive pulmonary diseases (COPD; including overlap syndrome), and neuromuscular and chest wall diseases (CWD) are presently the most frequent indications for HMV. Although practices may vary from one Canton (region) or University Hospital to another, trends follow the practices of other European countries.

\subsection{General Comments and Caveats}

Although patients on long-term home NIV are a very heterogeneous population, they share a certain number of characteristics:

- They often have several comorbidities (most often cardiovascular, cerebro-vascular or neurological disorders) [4].

- They are increasingly overweight or obese $[4,17]$.

- Mean age of this population is increasing $[4,17]$.

- Mild or moderate cognitive impairment may coexist with the underlying pathology (i.e., severe COPD [18, 19], advanced amyotrophic lateral sclerosis (ALS) [2022], some chronic neuromuscular diseases (NMD), very old subjects, sequelae of acute or chronic cerebral traumatic or non-traumatic lesions...).

- They may represent a considerable burden for care providers.

The follow-up of patients on NIV must therefore deal with all these aspects, in close collaboration with primary care physicians and the local healthcare network. Because many of the disorders leading to chronic hypercapnic respiratory failure (CHRF) are rare, the pulmonologist is often referred to as an expert and healthcare coordinator.

\subsection{Choice of Ventilators and Ventilator Modes}

Table 2 summarizes the ventilator modes most commonly used for long-term NIV [23]. In long-term NIV, bi-level positive pressure support ventilation in spontaneous/timed mode (PSV-ST; Table 2) is presently the most commonly used mode in clinical practice. These recommendations will therefore focus on this mode and will comment on the specifics of other ventilator settings in certain indications. A reminder of the basic settings for PSV-ST is provided in Figures 2 and 3. The reader is also provided with ventilator settings used in Swiss publications as an indication of possible settings (online supplement; see www.karger.com/doi/10.1159/000510086 for all online suppl. material) $[4,24]$. Volumetric ventilation is mainly considered in case of failure of PSV or pressurecontrolled ventilation (PCV), in some NMD, in very severe OHS, and in difficult cases of patient ventilator 
Fig. 1. Mechanisms implicated in chronic hypercapnic respiratory failure.

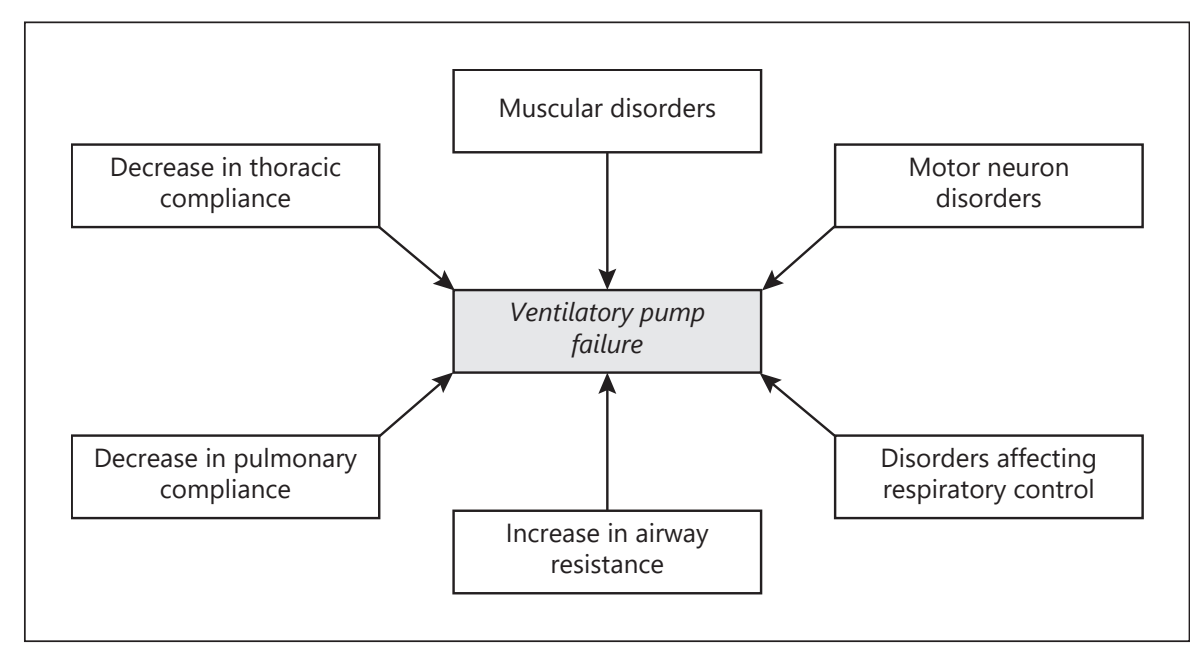

asynchrony (e.g., paradoxical adduction of vocal cords in ALS) [25]. Volumetric ventilators have been considered historically as "default devices" in invasive ventilation (i.e., ventilation by tracheostomy), although invasive ventilation with PSV and appropriate humidification is clearly feasible if appropriate humidification is ensured [26].

A distinction between ventilators for home care must be made between "Life-support devices" (with EU certification, compatibility with simple or double respiratory circuit and non-rebreathing expiratory valve, built-in battery of $>8 \mathrm{~h}$ of autonomy and "full range" of alarms including: electrical failure, patient disconnection, high non-intentional leaks, changes in minute ventilation), "Life-sustaining devices" (built-in battery not fulfilling life support criteria, basic range of alarms) and other home care devices (no built-in battery, minimal or no alarms) [27]. Ventilators with a built-in battery are the recommended devices for patients requiring more than $16 \mathrm{~h} /$ day of ventilatory support. For these patients (see section 7.1. on dependent patients), prescription of a second ventilator is recommended.

These recommendations will not address the issue of automated modes (Table 2). Over the past 15 years, a multitude of automated ventilator modes have been proposed by the industry. This trend started with volume-targeted devices (AVAPS, IVAPS), and complexity increased with the addition of auto-titrating expiratory positive airway pressure (EPAP), pressure support, and backup respiratory rate (BURR) [28-33]. Some devices also provide preset modes for obstructive or restrictive disorders. These modes are the result of a very sophisticated engineering and technical research. They are not however "fail-safe."
Table 1. Most frequent indications for long-term ventilation

1. Obstructive lung disorders

a. Chronic obstructive pulmonary disease (COPD)

b. Overlap syndrome

c. Diffuse bronchiectasis

d. Bronchiolitis obliterans

e. Cystic fibrosis

2. Obesity-hypoventilation syndrome

3. Restrictive chest wall and parenchymal disorders other than obesity-hypoventilation

a. Kyphoscoliosis and other chest wall deformities

b. Ankylosing spondylitis

c. Chest trauma

d. Sequalae of tuberculosis and/or thoracoplasty and/or thoracic surgery for cancer

e. Restrictive pleural diseases

4. Neuromuscular disorders (see Table 4)

5. Sleep-related breathing disorders

a. Obstructive sleep apnea

b. Central sleep apnea

This table does not provide all indications for NIV: it lists the most frequent and common indications within the diagnostic categories provided.

None of these options has, to date, been proven superior to conventional titration of bi-level PPV [28, 32, 34-40]. They are at best "non-inferior" to individually titrated settings. They may have a favorable impact on time needed to reach satisfactory ventilator parameters in some clinical settings. 
Table 2. Ventilator modes available on most devices used for home noninvasive ventilation (adapted from Schwarz and Bloch [23])

\begin{tabular}{|c|c|c|}
\hline Abbreviation & Mode & Settings* \\
\hline CPAP & $\begin{array}{l}\text { Continuous positive airway } \\
\text { pressure }\end{array}$ & CPAP pressure with additional options according to manufacturer \\
\hline PSV-S & $\begin{array}{l}\text { Pressure support ventilation, } \\
\text { spontaneous mode }\end{array}$ & $\begin{array}{l}\mathrm{IPAP}, \mathrm{EPAP}, \mathrm{TI}_{\mathrm{MIN}}, \mathrm{TI}_{\mathrm{MAX}} \text {, sensitivity of inspiratory and expiratory (cycling) } \\
\text { triggers, inspiratory rise time, fall time }\end{array}$ \\
\hline PSV-ST & $\begin{array}{l}\text { Pressure support ventilation, } \\
\text { spontaneous/timed mode }\end{array}$ & $\begin{array}{l}\text { IPAP, EPAP, respiratory back-up rate, } \mathrm{TI}_{\mathrm{MIN}}, \mathrm{TI}_{\mathrm{MAX}} \text {, or fixed } \mathrm{TI}^{* *} \text {; sensitivity of } \\
\text { inspiratory and expiratory (cycling) triggers, inspiratory rise time, fall time }\end{array}$ \\
\hline PSV-T & $\begin{array}{l}\text { Pressure support ventilation, } \\
\text { timed mode }\end{array}$ & $\begin{array}{l}\text { IPAP, EPAP, respiratory frequency, } \mathrm{TI}_{\mathrm{MIN}}, \mathrm{TI}_{\mathrm{MAX}} \text {, or fixed } \mathrm{TI} \text {, sensitivity of } \\
\text { expiratory (cycling) trigger, inspiratory rise time, fall time }\end{array}$ \\
\hline (a)PCV & $\begin{array}{l}\text { (Assisted) pressure control } \\
\text { ventilation }\end{array}$ & $\begin{array}{l}\text { IPAP, EPAP, respiratory frequency or respiratory back-up rate (in assisted } \\
\text { mode), TI (TI:TE), sensitivity of inspiratory trigger (in assisted mode), } \\
\text { inspiratory rise time, fall time }\end{array}$ \\
\hline \multicolumn{3}{|c|}{$\begin{array}{l}\text { IPAP, inspiratory positive airway pressure; } \mathrm{EPAP} \text {, expiratory positive airway pressure; } \mathrm{TI} \text {, inspiratory time; } \mathrm{TI}_{\mathrm{MIN}}, \text { minimal inspiratory } \\
\text { time; } \mathrm{TI}_{\mathrm{MAX}} \text {, maximal inspiratory time; } \mathrm{TI} \text {, fixed inspiratory time; } \mathrm{V}_{\mathrm{T}} \text {, tidal volume; } \mathrm{VA} \text {, alveolar ventilation. Fall time refers to time set } \\
\text { for passage from inspiratory to expiratory airway pressure (see Fig. } 2 \text {, top). } \\
* \text { Specific settings for modes described may not be available in all ventilators, depending on manufacturer and device. }{ }^{* *} \text { Options for } \\
\text { inspiratory time (TI) settings depend on device and mode. Settings for TI may apply to patient-triggered cycles and/or controlled cycles. } \\
\text { See text section } 1.5 \text {. }\end{array}$} \\
\hline
\end{tabular}

The SIG group recommends that the use of automated modes is left to the discretion of the clinician, with the following important caveats:

- Automated modes are not presently recommended as a default option.

- Because most of these modes have not been independently validated or proven to be superior to manual titration, the authors recommend having a low threshold for checking the adequacy of NIV by nocturnal polygraphy/polysomnography when using automated modes.

The authors also recommend using modes and devices with which one is familiar, since performance of NIV devices is heterogeneous and devices have their specific algorithms.

\subsection{Comments on Specific Ventilator Settings (Table 2)}

Ramp or SoftStart options. Several devices for home NIV provide an option allowing a progressive increase in expiratory pressure values and, in some cases, of pressure support (PS = IPAP - EPAP). This "comfort option," derived from the ramp option commonly used for patients treated by CPAP for OSA, can be problematic in patients under NIV, and even a source of discomfort. If used repeatedly, it can also compromise the efficacy of ventilation. In a recent case series highlighting the drawbacks of this option, the authors discourage the use of this option [41]. If used, initial pressure support should be at least 5-6 $\mathrm{cm} \mathrm{H}_{2} \mathrm{O}$, time to attain set pressure should be as short as possible and relevance of this option should be regularly reevaluated [41].

Pre-set decline of pressure support (Soft Stop, Ramp down). This option has been devised for patients with "deventilation dyspnea" (i.e., severe transient dyspnea after interruption of ventilation) although it has not been validated in independent clinical studies [42]. The ramp is triggered by the patient prior to his/her interruption of NIV: when activated, pressure support will decline progressively from its preset value to 0 , over a predefined time (usually 10-20 $\mathrm{min}$ ). The ventilator then remains in a CPAP mode at EPAP value until it is stopped by the patient.

Rise time. Figure 2 (top) shows how rise time impacts on pressurization. Short values decrease work of breathing [43] but may be perceived as uncomfortable or cause leaks. In obstructive lung diseases, short rise times $(\leq 150$ $\mathrm{ms}$ ) favor a shorter inspiratory time (TI) and a favorable 


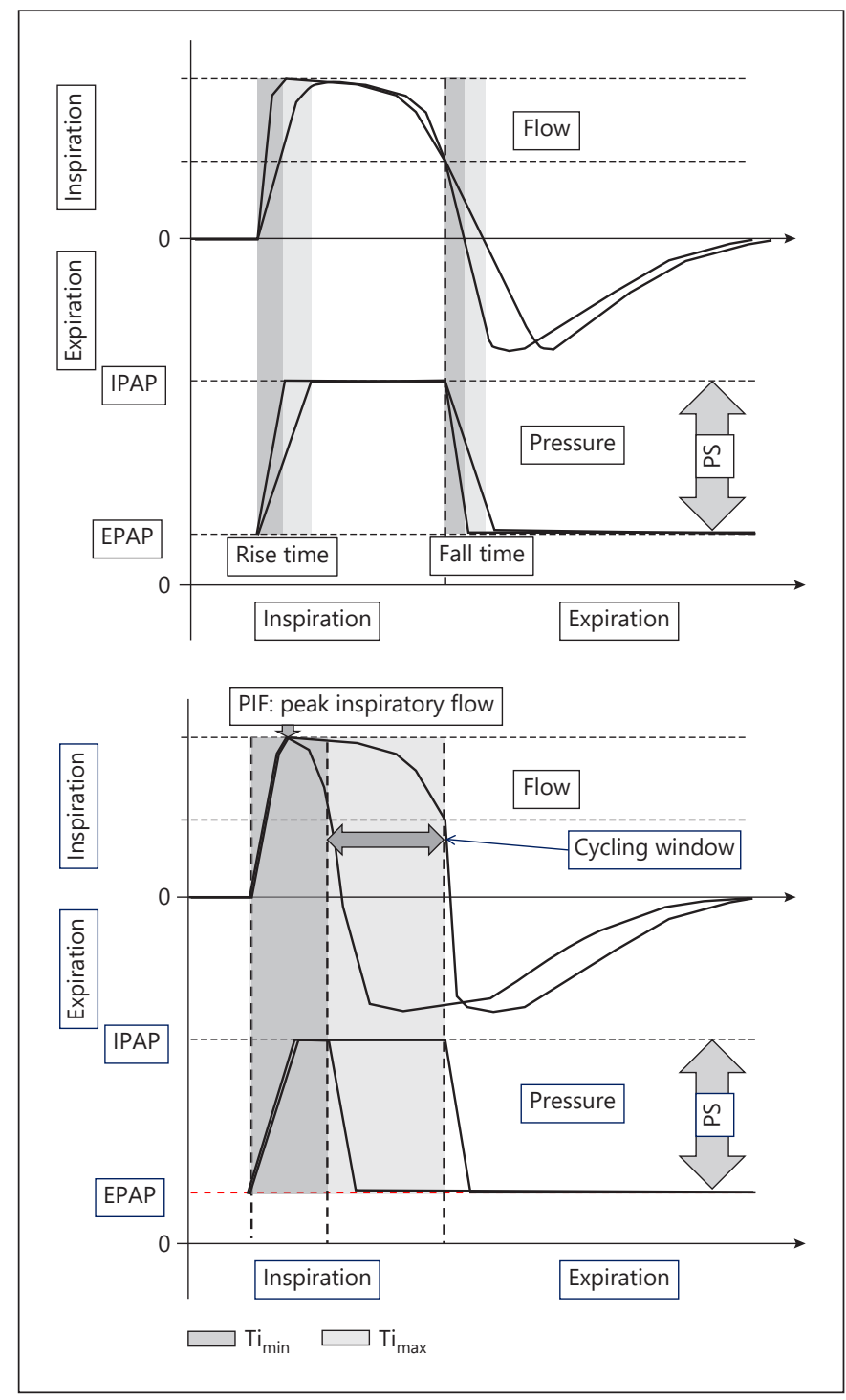

Fig. 2. Settings for bi-level positive pressure ventilation. PS, pressure support ( $\triangle[$ IPAP-EPAP]); IPAP, inspiratory positive airway pressure; EPAP, expiratory positive airway pressure; $\mathrm{TI}_{\mathrm{MIN}}$, minimal inspiratory time; $\mathrm{TI}_{\mathrm{MAX}}$, maximal inspiratory time. Top: impact of changes in rise time and fall time on pressurization. Bottom: Cycling window. Cycling occurs between $\mathrm{TI}_{\mathrm{MIN}}$ and $\mathrm{TI}_{\mathrm{MAX}}$. Settings subject to variations according to device.

Fig. 3. Cycling settings. PS: pressure support ( $\triangle[$ IPAP-EPAP]). IPAP: inspiratory positive airway pressure; EPAP, expiratory positive airway pressure; PIF, peak inspiratory flow; $\mathrm{P}_{\mathrm{AW}}$, airway pressure. Impact of cycling criterion on pressurization and I:E ratio. A cycling criterion at a high percentage of PIF (top) favors a low I:E ratio, a longer expiration, and is appropriate in obstructive lung disorders. Conversely (bottom), a cycling criterion at a low percentage of PIF favors a higher I:E ratio, prolongs insufflation, and is recommended in restrictive lung disorders such as OHS.

Long-Term Mechanical Ventilation:

Recommendations of the SSP

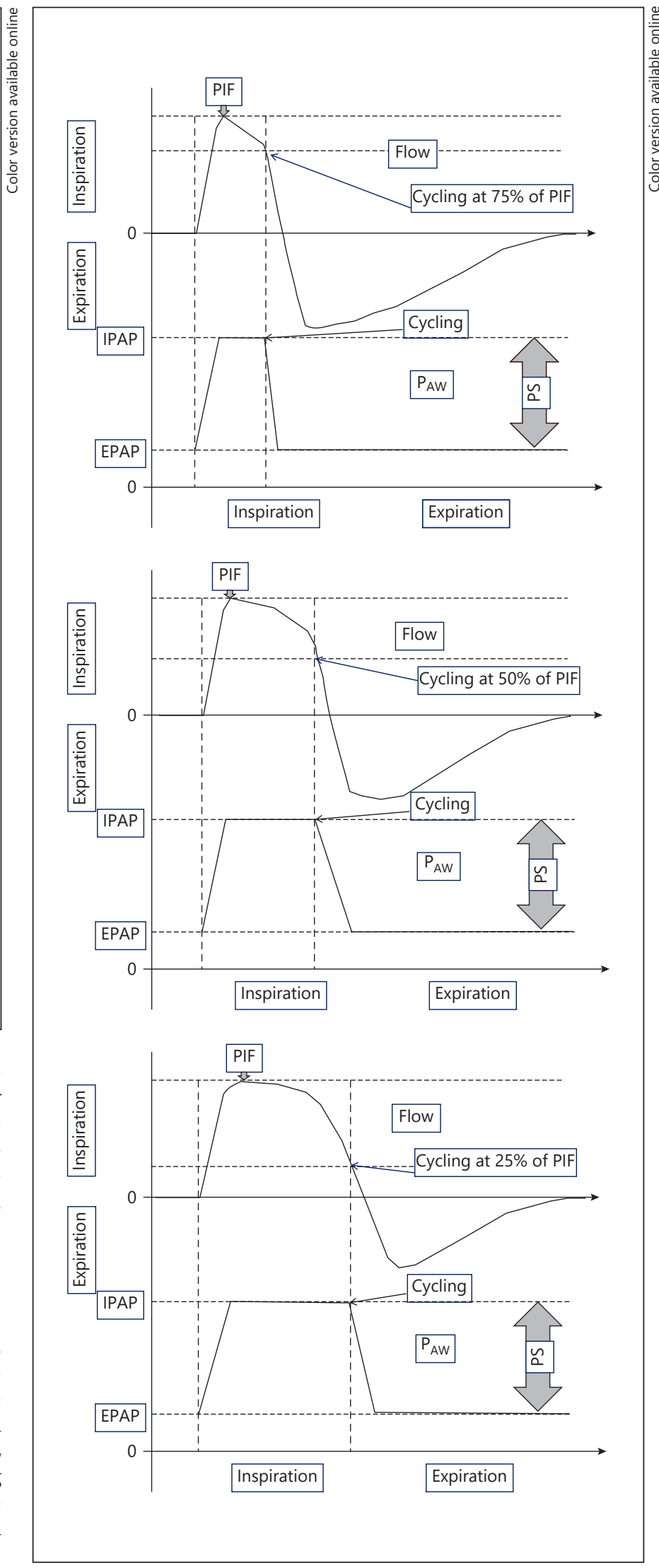


I:E ratio (e.g., $\approx 1: 3$ ). Conversely, rise times of $150-250$ $\mathrm{ms}$ are commonly used in restrictive lung diseases $[4,14$, 24]. Longer rise times may impinge on pressurization time and affect efficacy of ventilation. Values above 300 $\mathrm{ms}$ are not recommended albeit for comfort reasons in a newly electively ventilated patient: this value should then progressively be decreased over time.

Inspiratory trigger. In most devices used for long-term ventilation, inspiratory triggers are flow-dependent and very sensitive. Inspiratory trigger sensitivity scales vary according to device and manufacturer: they may be expressed as non-specific descriptors (i.e., high, medium, low), as arbitrary numerical units or as flow (L/min) required to trigger pressurization. Some devices provide algorithms with automated settings (e.g., Autotrak ${ }^{\circledR}$ ). Inspiratory trigger sensitivity seldom requires adjusting and can be set by default at mid-range values. Increasing inspiratory trigger sensitivity may be an option in advanced NMD when inspiratory muscles are severely weakened (e.g., advanced ALS or Duchenne muscular dystrophy). In this situation, polygraphic tracings or detailed analysis of ventilator curves may show patient-ventilator asynchrony (e.g., unrewarded inspiratory efforts) [44]. The risk associated with increasing sensitivity is the occurrence of auto-triggering which may be a source of discomfort and affect ventilator efficacy. In case of unrewarded inspiratory efforts, control of leaks and management of intrinsic positive end-expiratory pressure (PEEPi) should be optimized before adjusting inspiratory trigger $[44,45]$. PEEPi can be compensated by increasing EPAP values, and by optimizing the I:E ratio (decreasing TI and respiratory rate) and cycling criteria.

Expiratory trigger (cycling). Expiratory trigger (or cycling) setting is important for patient comfort, and prevention of patient-ventilator asynchrony and dynamic hyperinflation in COPD [46]. It also contributes to improve V/Q matching in severe restrictive disorders (e.g., obesity-hypoventilation). Bench tests have shown that home ventilators tend to cycle prematurely when submitted to restrictive mechanics conditions, while delayed cycling occurs with default settings in obstructive lung conditions [47]. Cycling should be set at a high percentage of peak inspiratory flow (PIF) in obstructive lung diseases and at a low percentage of PIF in restrictive disorders such as obesity-hypoventilation (Fig. 3). The impact of cycling on the I:E ratio is illustrated in Figure 3.

Inspiratory time. As mentioned in Table 2, options for TI settings vary considerably from one device to another and according to mode. TI may be either allowed to vary in a cycling window between a minimal $\left(\mathrm{TI}_{\mathrm{MIN}}\right)$ and max- imal value ( $\left.\mathrm{TI}_{\mathrm{MAX}}\right)$ or set at a fixed value (Fig. 2, bottom). It may also be determined automatically by an algorithm. Some devices distinguish between controlled and triggered cycles and apply TI settings only to one or the other. Clinicians must explore the specific options available on the device they are using. In all cases, TI must be above rise time [48]. A minimal value of $0.5 \mathrm{~s}$ is recommended.

Fall time (Fig. 2, top). A few ventilators allow to set the time required for pressure to drop from inspiratory to expiratory set values (i.e., cycling). Manufacturers suggest that this may be used to prevent dynamic hyperinflation and to avoid premature expiratory closing of peripheral airways. This interesting option requires further clinical validation.

\subsection{Humidifiers}

Roughly $70 \%$ of patients on home NIV use heated humidifiers (built-in or add-on) [4]. Humidification decreases dehydration of mucosal membranes, decreases upper airway resistance, and improves airway mucociliary clearance $[49,50]$. Although it does add some complexity to the treatment, it is recommended to add active humidification with a low threshold. Use of distilled or demineralized water is recommended, with daily changing, and rinsing/washing of container.

\subsection{Tubings, Circuits and Filters}

Respiratory circuits (i.e., the tubing between the ventilator and the interface or tracheal canula) are either single- or double-limb (Fig. 4).

Double-limb circuits are mostly used in acute care settings (ICU) [23, 51]. One tube is for inspiration, the other for expiration. Active unidirectional valves redirect exhaled air through the expiratory circuit towards the respirator thus avoiding any risk of rebreathing. These circuits (and associated interfaces) are non-vented (i.e., without exhalation port). A minimal expiratory flow (PEEP or EPAP) is not required to prevent $\mathrm{CO}_{2}$ rebreathing, and thus PEEP can be set at 0 . Double-limb circuits allow direct measurement of expired volume (VE). Inspiratory and expiratory tubes may be coaxial: this allows passive heating of the inspired gas by expiratory flow.

For home ventilation, single-limb circuits are most commonly used $[23,51]$. They are less cumbersome. To prevent $\mathrm{CO}_{2}$ rebreathing, the circuit must have either an active expiratory valve, placed close to the mask to minimize dead space, or a passive calibrated exhalation port (i.e., a passive leak valve) which can be either integrated in the interface (vented mask) or in the circuit (vented circuit). The active valve opens only during expiration. 


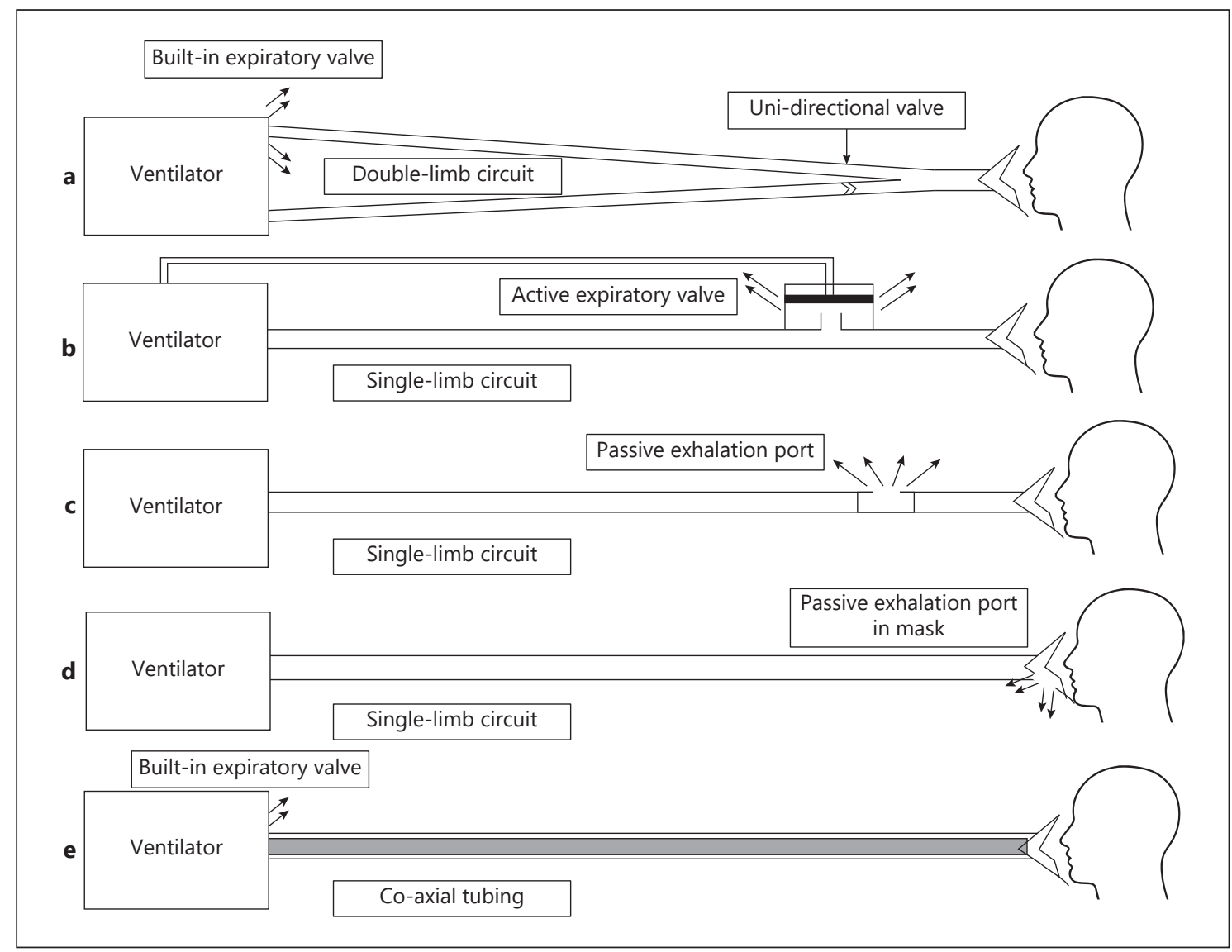

Fig. 4. Tubings. a Double-limb circuit with unidirectional valve to avoid rebreathing, non-vented mask, and expiratory valve built in the ventilator. b Single-limb circuit with active expiratory valve and non-vented mask. c Single-limb circuit with passive exhalation port (on tubing, close to non-vented mask). d Single-limb circuit with passive exhalation port incorporated into vented mask. e Coaxial tubing, unvented mask, and expiratory valve built in the ventilator.

The passive port creates an intentional continuous air leakage and requires a minimal expiratory pressure (usually $3-4 \mathrm{~cm} \mathrm{H}_{2} \mathrm{O}$ ) to prevent rebreathing and flush the $\mathrm{CO}_{2}$ from the circuit. Because of their ease of use, vented masks are most often used for home NIV. One disadvantage of using a single-limb circuit is that unintentional leaks and tidal volume (VT) provided by ventilator software are estimated and not measured. Bench studies have shown that VT (and therefore VE) is most often underestimated [52-54], with a high variability in bias reported (66-236 mL reported by Contal et al. [53]). In case of unintentional leaks, however, VT may be overestimated. The precision of the estimation of VT is not only influenced by unintentional leaks but also by the breathing pattern and the underlying lung mechanics: in one benchtest study, underestimation was more important in obstructive than in restrictive settings [52]. This may inter- fere not only with monitoring of VT but also with the performance of ventilators in volume-targeted modes [52].

Mouthpiece ventilation (MPV: most often used for daytime ventilation in neuromuscular disorders) can be provided with a single or a double-limb circuit and various types of mouthpieces [55-57]. Articulated support arms which can be fixed to wheelchairs are commercialized and allow easy positioning of mouthpiece. Recent multimodal ventilators provide either volume-cycled or pressure-cycled dedicated modes for MPV, and do not require exhalation valves.

Heated tubings may improve patient comfort and efficacy of NIV when using a heated humidifier. Although heated and humidified air can improve airway mucociliary clearance, management of secretions, and decrease upper airway resistance [49], condensation may cause pa- 

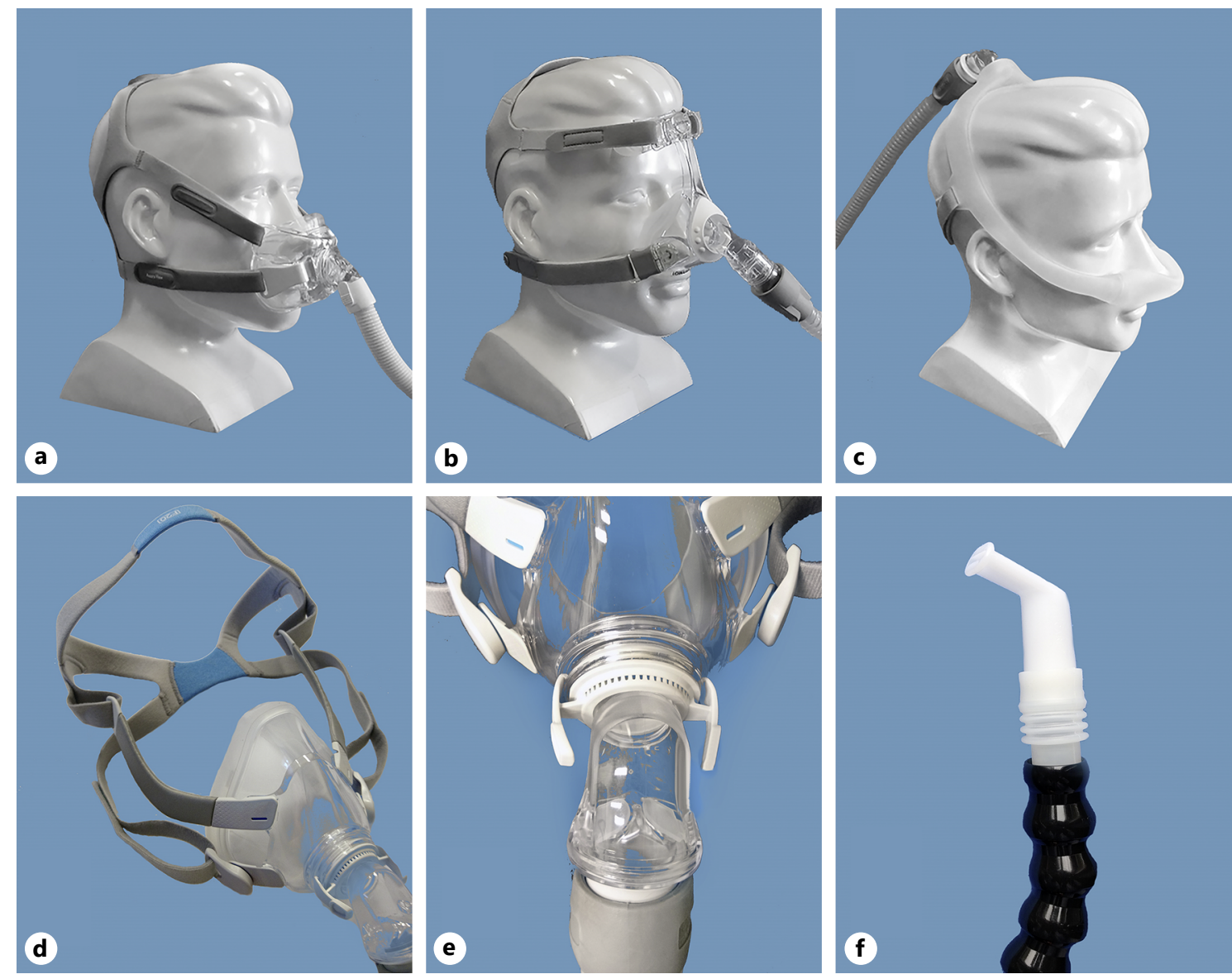

Fig. 5. Interfaces for noninvasive ventilation. a Oro-nasal mask. b, c Nasal masks. d Facial mask. e Detail of exhalation valve of mask. $\mathbf{f}$ Mouthpiece. From Schwarz and Bloch [23].

tient-ventilator asynchrony, and interfere with pressurization [50]. Heated tubings prevent condensation that may occur when using a heated humidifier. A tissue hose around the tubing can also decrease the temperature gradient and prevent condensation in ventilator tubing.

Antibacterial filters are recommended when using the same ventilator for different patients (hospital setting). For home NIV, there is no formal recommendation as to their use. Heat- and moisture-exchanging filters may prevent mucosal dryness when the use of an electrically heated humidifier is not feasible, such as during travel or ambulation.

Supplemental oxygen is provided by an oxygen blender in most hospital (ICU) ventilators. For home NIV, oxygen is added to the breathing circuit when needed. In this setting, effective oxygen delivery and $\mathrm{FiO}_{2}$ depend not only on oxygen flow but also on intentional and unintentional leaks, site of oxygen administration on ventilator circuit, site of exhalation port, ventilator settings and re- spiratory drive [58]. There is thus no simple relation between oxygen requirements at rest without NIV and oxygen flow required on the ventilator circuit, and titration of oxygen flow requires monitoring of $\mathrm{SpO}_{2}$. When the circuit is vented, the highest oxygen concentration is achieved with oxygen added to the mask: this may be relevant in rare situations of very high $\mathrm{FiO}_{2}$ requirements [58]. In other cases, the most appropriate site of oxygen adjunction is close to the ventilator, which improves comfort. Certain homecare ventilators have a special oxygen port for connection of the tubing from a low-pressure oxygen source such as an oxygen concentrator. This port closes automatically if the ventilator is turned off thereby preventing the risk of fire hazard by continuous oxygen flow into an inactive ventilator. Oxygen flow must be titrated by pulse oximetry or arterial blood gas analysis.

Aerosols can be delivered during NIV. With a singlelimb circuit, vibrating mesh nebulizers are more efficient than jet nebulizers. They must be placed as close as pos- 
sible to the mask, between the mask and the exhalation port $[59,60]$.

\subsection{Interfaces}

The number of interfaces made available by the industry is constantly increasing, providing more and more options for improving patient comfort. It is important to work with healthcare providers or healthcare workers who are up to date with the most recent interfaces. At present, facial masks are the most widely used in published data concerning long-term NIV [4, 61-63]. However, there is an increasing awareness of the caveats associated with facial masks, that is, an increase in upper airway resistance caused by retropulsion of the jaw, which may induce or prevent the correction of upper airway obstruction [25]. Oro-nasal masks (Fig. 5) are being increasingly used, are less cumbersome, and may be an alternative to facial masks either because of pressure sores on the nose or claustrophobia. Although nasal masks may favor mouth leaks during the night, this can be at least partially prevented by the use of chin straps that secure the position of the jaw although they cannot prevent leaks at the lips. Nasal prongs are a useful option for daytime ventilation, for situations requiring low pressure support, although they may tolerate up to $25 \mathrm{~cm} \mathrm{H}_{2} \mathrm{O}$ of inspiratory pressure. Mouthpiece ventilation is also an excellent option for daytime ventilation in NMD. Custom-made masks are seldom required.

Hygiene of masks is critical, is important for prevention of skin lesions and leaks and requires repeated education for patients and caregivers. All parts of the mask, especially the cushion and the ventilation port (exhalation valve), should be cleaned after each use with lukewarm water and mild soap.

\subsection{Where, How and by Whom Should Home NIV Be} Implemented and Followed?

In Switzerland, long-term HMV, irrespective of the diagnosis or setting, must be prescribed by a certified pulmonologist who can initiate the treatment and provide appropriate instruction to the patient and caregivers. The indication for HMV is usually reviewed by the medical advisor of the medical insurance.

Data from the GLS provide an indication as to actual practices in Switzerland for home NIV [4], which may evolve.

- Half of all long-term NIV treatments are started electively, and half in an emergency setting.

- Roughly $80 \%$ of all patients start their treatment as inpatients (electively or after an acute exacerbation).
- On a long-term basis, in the GLS study, 1/3 of all patients were followed exclusively by a pulmonologist in private practice. Thus $2 / 3$ of long-term NIV patients were followed by a hospital with or without a pulmonologist in private practice.

The role of healthcare providers and pulmonologists in private practice as actors in home NIV is increasing in Switzerland. This practice differs from that of several European countries. In the Netherlands, in Germany, in Denmark, or in Norway for instance, patients on long-term NIV are treated and followed exclusively by expert hospitals.

The SIG suggests the following recommendations:

- The goal of NIV is to improve symptoms and healthrelated quality of life, decrease hospital admissions, correct hypoventilation, and optimize $\mathrm{SpO}_{2}$ to improve survival, prevent cardiovascular complications such as pulmonary hypertension and cor pulmonale. If nocturnal $\mathrm{PtcCO}_{2}$ and sleep-related breathing disorders (SRBD) are controlled, but $\mathrm{SpO}_{2}$ remains low, addition of oxygen on the ventilator circuit may be considered.

- Elective implementation of NIV may be performed in a hospital, in an outpatient clinic, or at the patient's home by an experienced team (healthcare provider) led by an experienced pulmonologist $[64,65]$.

- Outpatient initiation of NIV is a possible option in stable patients. It can be recommended for example in patients with a prior experience of CPAP, and in elective situations of patients with SRBD, OHS, or $\mathrm{NMD}$, with monitoring of blood pressure and $\mathrm{SpO}_{2}$ under NIV and follow-up of arterial or transcutaneous $\mathrm{CO}_{2}\left(\mathrm{PtcCO}_{2}\right)$.

- Frequency of follow-up evaluations (modalities, timing) depends on the underlying pathology, and is usually performed every 3-12 months. A follow-up evaluation is in most cases recommended at least once a year.

- Modalities of follow-up have been reviewed in detail by the SomnoNIV group (see Fig. 6) [66] and include clinical examination, targeted medical history, arterial blood gases $(A B G)$, nocturnal pulse oximetry, downloading and analysis of ventilator software, and, when indicated, more detailed sleep studies or lung function tests.

- When available, use of nocturnal transcutaneous $\mathrm{CO}_{2}$ measurement is recommended, preferably at the patient's home, especially in subjects under oxygen therapy or with persistent diurnal hypercapnia [66$68]$. 


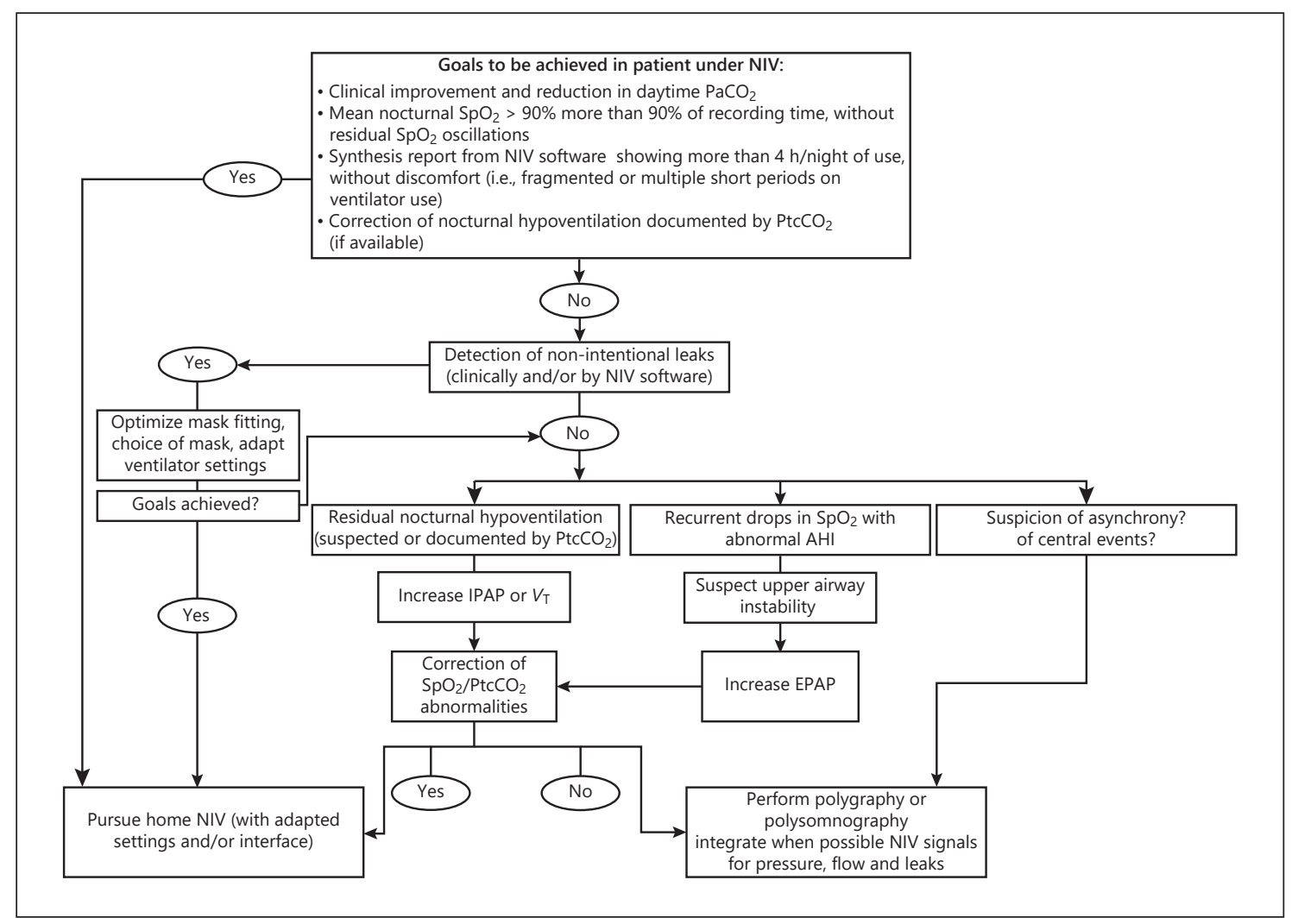

Fig. 6. Proposed algorithm for monitoring patients under long-term NIV. Adapted from Janssens et al. [66].

\subsection{Tools for Measuring $A B G$}

Correction of $A B G$ and more specifically, of diurnal and nocturnal $\mathrm{PaCO}_{2}$ and respiratory acidosis, is one of the main goals of long-term mechanical ventilation. Measurement of daytime ABG, most often through puncture of the radial artery, is considered as a gold standard procedure. However, it has its drawbacks: it may be painful, awakens the patient if performed at night, and requires expertise. Furthermore, it is only representative of the moment when sampling was performed and does not actually reflect the time course of $\mathrm{PaCO}_{2}$ during the night [66].

Alternative tools may provide useful information as to ABG while decreasing patient discomfort.

- Capillary arterialized samples are usually taken at the earlobe after application of a vasodilating gel. They have been reported as reliable for $\mathrm{pH}$ and $\mathrm{PaCO}_{2}$, with only small biases and limits of agreement in patients with various pulmonary disorders and in a meta-analysis $[69,70]$. Results for $\mathrm{PaO}_{2}$ are less reliable, with an overall underestimation of arterial $\mathrm{PaO}_{2}$ by the capillary technique $[69,71]$. Capillary samples require fur- ther validation in a population of subjects with $\mathrm{CHRF}$ $[72,73]$.

- End-tidal $\mathrm{CO}_{2}$ : Although routinely used by anesthetists during surgical procedures, the reliability of $\mathrm{ETCO}_{2}$ as a surrogate of ABG is insufficient. ETCO systematically underestimates $\mathrm{PaCO}_{2}$. Agreement between $\mathrm{PaCO}_{2}$ and $\mathrm{ETCO}_{2}$ values is affected by V/Q mismatch, by physiological dead space, by pulmonary vascular disorders and by ventilatory mode (expiration time) and thus values provided by $\mathrm{ETCO}_{2}$ are considered unreliable in adult populations [74]. It must be emphasized that a normal $\mathrm{ETCO}_{2}$ does not exclude hypercapnia, whereas a high $\mathrm{ETCO}_{2}$ is strongly suggestive of hypercapnia, although it may underestimate its severity $[66,74]$. The SIG suggests limiting the use of $\mathrm{ETCO}_{2}$ to special situations, for example, for children with NMD.

- Transcutaneous capnography $\left(\mathrm{PtcCO}_{2}\right)$ : $\mathrm{PtcCO}_{2}$ measurements are presently considered reliable in hemodynamically stable patients and use of $\mathrm{PtcCO}_{2}$ devices has improved in user-friendliness. Devices are non- 
invasive, and well tolerated at a probe temperature of $42^{\circ} \mathrm{C}$ for $8-12 \mathrm{~h}$ [75]. Recent studies have reviewed the performances of several devices and shown that they have acceptable biases and limits of agreement, when compared to $A B G$, in patients with CHRF treated by long-term mechanical ventilation [67]. There are however a few limitations that the clinician must bear in mind: (1) there is a lag time between changes in $\mathrm{PaCO}_{2}$ and $\mathrm{PtcCO}_{2}$ of a few minutes which makes these devices unreliable for the detection of rapid changes in $\mathrm{PaCO}_{2}$ such as in OSA [76]; (2) most clinical studies show the occurrence of unpredictable errand values which require experience in tracing analysis and may be misleading [66]; (3) in spite of their apparent ease of use, $\mathrm{PtcCO}_{2}$ devices require a dedicated team with expertise: the number of unreliable traces increases when recordings are not organized by an experienced team.

- The question of defining what is an acceptable definition of nocturnal hypoventilation has been arbitrarily solved by expert-based suggestions published by the American Association of Sleep Medicine [77]. This subject is however still open to discussion, and minor changes in definitions of hypoventilation can have a substantial impact in clinical practice $[78,79]$.

\subsection{Frequent Side Effects of Mechanical Ventilation and Their Management}

On average, NIV is remarkably well tolerated. Adherence to treatment documented in recent Swiss studies, suggests that side effects are rarely important enough to compromise the pursuit of the treatment $[4,24]$.

A symptom-based pragmatic 11-item questionnaire targeting NIV-related discomfort has been recently made available for clinical practice ( $\mathrm{S}^{3}$-NIV questionnaire) [80].

Table 3 lists the most frequent side effects reported on NIV. Appropriate humidification and management of leaks are necessary to correct most causes of discomfort. Repeated education for the patient and caregivers to avoid skin lesions and ensure appropriate positioning of the interface are crucial. Settings must be adjusted to limit leaks and/or prevent abdominal distention and discomfort (i.e., rise time, level of pressure support, cycling criterion...).

A distressing symptom, referred to as "deventilation dyspnea," is the occurrence of severe dyspnea for minutes to hours after cessation of NIV. This is reported in severe COPD [42] but also in neuromuscular disorders or in obesity-hypoventilation. Specific strategies have been
Table 3. Most frequently reported side effects related to the use of noninvasive ventilation

Patient discomfort resulting from:

- unintentional leaks (around the interface or through the mouth)

- leak-induced xerostomia, xerophtalmia or conjunctival irritation

- pain caused by head gear or mask

- skin lesions, pressure sores and ulcerations

- nasal obstruction, congestion, rhinorrhea, nasal mucosal dryness

- inappropriate alarm settings

- abdominal distention

- perceived patient-ventilator asynchrony (delayed triggering, premature or delayed cycling, autotriggering...)

- disrupted sleep

- claustrophobia or anxiety related to interface

Adapted from Janssens et al. [251].

suggested for COPD: in these patients, deventilation dyspnea may result from progressive dynamic hyperinflation overnight [42]. Mechanisms involved in OHS or neuromuscular disorders are not described. Several home ventilators provide an option of progressive decrease in pressure support before cessation of NIV, triggered by the patient, which warrants further clinical testing.

Side effects related to invasive ventilation are discussed in section 7.4 .

\section{Obstructive Lung Diseases}

\subsection{General Comments}

Although practices vary widely from one country to another, COPD is either the most frequent or among the most frequent indications for long-term NIV in most European countries and represents on average $30 \%$ of the long-term NIV population [81,82]. Acute exacerbation of COPD is the main cause of acute hypercapnic failure requiring ventilatory support in the ICU: $44 \%$ of these patients are overweight or obese, and average BMI is $29.8 \pm$ $8.8 \mathrm{~kg} / \mathrm{m}^{2}$ [83]. In France, data from the multicentric French ANTADIR observatory (www.antadir.org; covering $\approx 7,000$ patients under NIV, 2011) document COPD as the second indication for NIV after SRBD. A recent Swiss descriptive study (GLS) showed that, among 489 stable patients on NIV in the cantons of Geneva and Vaud, 190 (39\%) had COPD. Median BMI was $28 \mathrm{~kg} / \mathrm{m}^{2}$ (IQR $21 ; 33)$ for COPD patients without OSA $(n=135)$, and 32 


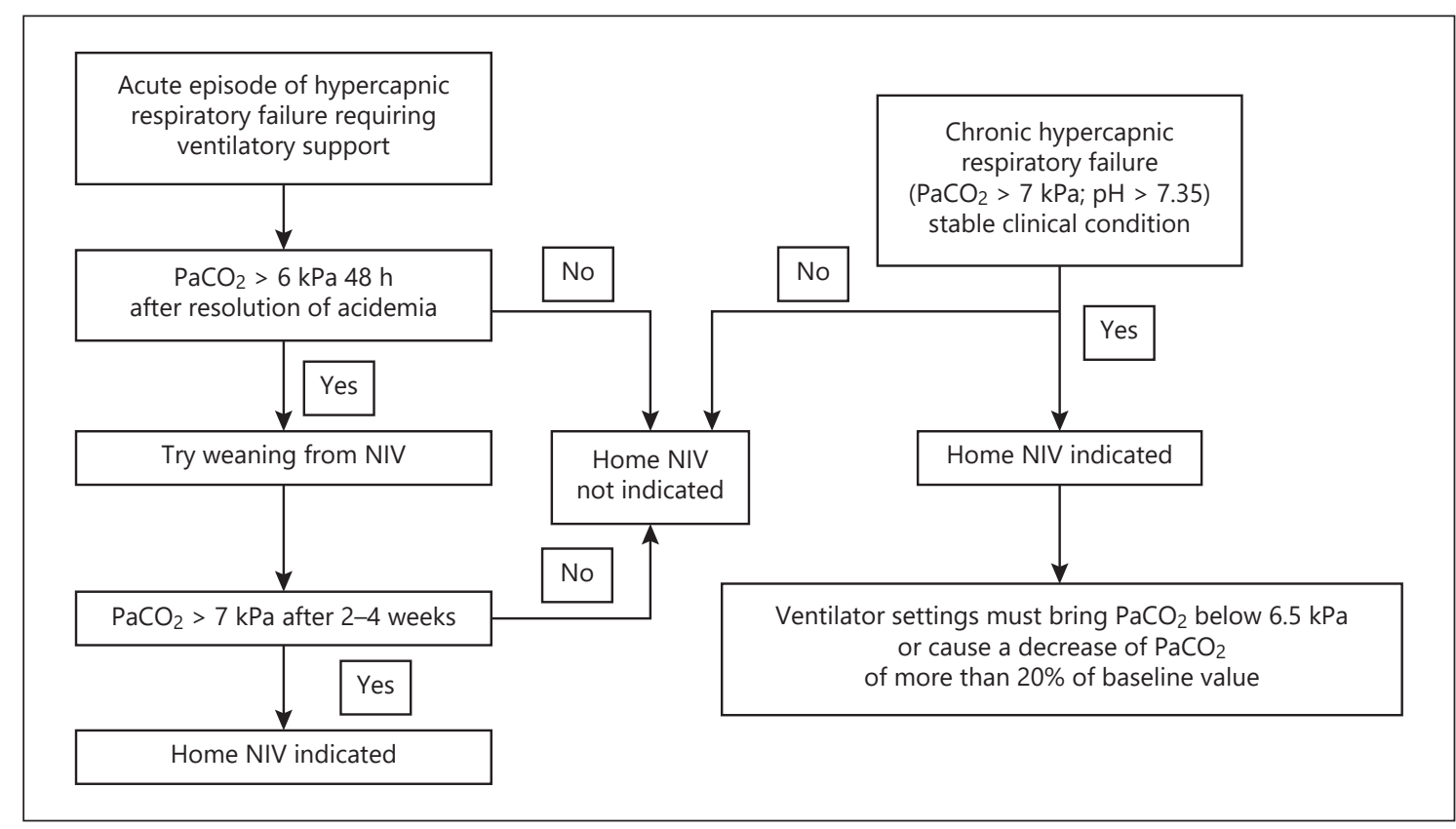

Fig. 7. Suggested algorithm for noninvasive ventilation (NIV) in COPD based on references [96, 97, 99].

$\mathrm{kg} / \mathrm{m}^{2}$ (IQR 28; 40) for those with overlap syndrome $(n=$ 55). These data thus show that the dominant phenotype among COPD requiring long-term NIV in our area is a population of comorbid frequently overweight or obese patients, with, in one third of cases, associated OSA. This must be kept in mind when analyzing the available evidence regarding long-term use of NIV in COPD.

Short-term studies have shown a benefit of so-called "high intensity NIV" (combining high IPAP values and high BURR) on pulmonary function tests (PFT), 6 min walk tests, $\mathrm{ABG}, \mathrm{V} / \mathrm{Q}$ ratio, and $\mathrm{HRQ}$ oL when compared to low-intensity NIV [84-86], without any major negative impact on quality of sleep [87]. Noteworthy is the fact that high-pressure NIV may affect cardiac function and must be applied with caution in patients with chronic heart failure, and should thus be initiated under monitoring in a hospital setting [88-90].

After decades of conflicting evidence regarding the long-term benefit and clinical impact of NIV in COPD [91-93], meta-analyses [94, 95], 3 recent randomizedcontrolled studies [86, 96, 97], and the report of an ERS task force have provided a partial scientific basis for the long-term use of NIV in COPD [98].

In 2014, Struik et al. [94] published a systematic review and meta-analysis, covering data concerning 245 COPD patients from publications compiled up to 2012: using IPAP levels of at least $18 \mathrm{~cm} \mathrm{H}_{2} \mathrm{O}$, using NIV for at least 5 h per night, and having a baseline $\mathrm{PaCO}_{2}$ of at least $55 \mathrm{~mm}$ $\mathrm{Hg}(7.3 \mathrm{kPa})$ were identified as factors predictive of an improvement in $A B G$ [67].

An important Dutch randomized controlled study (RESCUE trial) included COPD patients who remained hypercapnic $\left(\mathrm{PaCO}_{2}>6 \mathrm{kPa}[45 \mathrm{~mm} \mathrm{Hg}]\right)$ just after an acute episode of hypercapnic respiratory failure $(\mathrm{AEH}-$ RF) [97]: 201 COPD patients hospitalized for AEHRF were randomized $48 \mathrm{~h}$ after termination of ventilator support to long-term NIV $\left(n=101 ; \mathrm{PaCO}_{2}: 59.3 \pm 9 \mathrm{~mm}\right.$ $\mathrm{Hg}[7.9 \pm 1.2 \mathrm{kPa}] ; \mathrm{FEV}_{1}: 25.6 \pm 7.8 \%$ predicted) vs. usual care $\left(n=100 ; \mathrm{PaCO}_{2}: 57.7 \pm 9.7 \mathrm{~mm} \mathrm{Hg}[7.7 \pm 1.3 \mathrm{kPa}]\right.$; $\mathrm{FEV}_{1}: 25.7 \pm 8.6 \%$ predicted). Average BMI was $<25 \mathrm{~kg} /$ $\mathrm{m}^{2}$ in both groups. One year later, the authors found no significant benefit of NIV on survival, hospital readmissions or HRQL when compared to the control population. Furthermore, $\mathrm{PaCO}_{2}$ decreased both in the NIV and in the control group. It was concluded that recovering from an AEHRF is not per se a justification for longterm NIV.

A British multicentric RCT (HOT-NIV trial) included 116 COPD patients recovering from an AEHRF with persistent hypercapnia $\left(\mathrm{PaCO}_{2}>53 \mathrm{~mm} \mathrm{Hg}, 7.1 \mathrm{kPa}\right) 2-4$ weeks following an acute hypercapnic exacerbation requiring NIV [99]. Patients with a BMI $>35 \mathrm{~kg} / \mathrm{m}^{2}$, OSA, or other causes of CRF (NMD, CWD) were excluded. Patients were randomized to home oxygen therapy 
(HOT) versus HOT and high-intensity NIV. NIV increased the time to hospital readmission by approximately 3 months (4.3 months [IQR 1.3-13.8] for HOTNIV vs. 1.4 months [IQR 0.5-3.9] for HOT) and reduced the likelihood of occurrence of the primary endpoint readmission or death within 12 months - by ca. $50 \%$ (HR 0.49 [95\% CI 0.31-0.77, $p=0.002]$ ). The number needed to treat to avoid one readmission or death in this specific population was 6 . Adjunction of NIV to HOT appears therefore useful in non-obese, non-apneic COPD who remain hypercapnic 2-4 weeks after an AEHRF episode.

For COPD patients in a stable clinical condition (more than 4 weeks after an AEHRF), a German and Austrian multicentric prospective RCT compared 102 patients treated by NIV $\left(\mathrm{FEV}_{1}: 26 \pm 11 \%\right.$ predicted, BMI $24.8 \mathrm{~kg} /$ $\mathrm{m}^{2}, \mathrm{PaCO}_{2}: 58.5 \pm 6 \mathrm{~mm} \mathrm{Hg}$ [7.8 $\left.\left.\pm 0.8 \mathrm{kPa}\right]\right)$ versus 93 on usual care $\left(\mathrm{FEV}_{1}: 27 \pm 9 \%\right.$ predicted, BMI $24.5 \mathrm{~kg} / \mathrm{m}^{2}$, $\mathrm{PaCO}_{2}: 57.7 \pm 5.2 \mathrm{~mm} \mathrm{Hg}$ [7.7 $\left.\pm 0.7 \mathrm{kPa}\right]$ ) [96]. Inclusion criteria were: having a $\mathrm{PaCO}_{2}$ of at least $7 \mathrm{kPa}(52.5 \mathrm{~mm}$ $\mathrm{Hg}$ ), and a $\mathrm{pH}>7.35$ before randomization. They were followed for 12 months. High-intensity NIV was adjusted to reduce $\mathrm{PaCO}_{2}$ below $48.7 \mathrm{~mm} \mathrm{Hg}(6.5 \mathrm{kPa})$, or at least $20 \%$ lower than the baseline value. In this specific population, NIV significantly improved baseline $\mathrm{PaCO}_{2}, \mathrm{HRQL}$, and survival (mortality was $33 \%$ in the control group and $12 \%$ in the NIV group). It also reduced hospital admissions. The number needed to treat to avoid one death by NIV in this setting was 5.

Based on this evidence and closely following the most recent guidelines published by an ERS task force on NIV in COPD, the SIG suggests the following recommendations (all conditional) [98] (Fig. 7):

- Long-term NIV should be used in chronic stable hypercapnic patients $\left(\mathrm{PaCO}_{2}>7 \mathrm{kPa}[52.5 \mathrm{~mm} \mathrm{Hg}]\right)$ with severe $C O P D^{1}$.

- Long-term NIV should be implemented after an AEH$R F$ only if hypercapnia $\left(\mathrm{PaCO}_{2}>7 \mathrm{kPa}[52.5 \mathrm{~mm} \mathrm{Hg}]\right)$ persists 2-4 weeks after the acute episode.

- The potential benefit of long-term NIV for recurrent AERHF without persistent hypercapnia at 2-4 weeks remains undetermined.

- When implementing NIV in COPD patients with CHRF, settings should be adjusted to decrease $\mathrm{PaCO}_{2}$ below $6.5 \mathrm{kPa}(50 \mathrm{~mm} \mathrm{Hg})$ or reduce $\mathrm{PaCO}_{2}$ levels by more than $20 \%$ of baseline level.

- When implementing NIV in COPD patients with CHRF, fixed PSV should be preferred to auto-titrating modes as first-choice mode.

Long-Term Mechanical Ventilation:

Recommendations of the SSP
NIV may also be considered as a component of palliative care and symptomatic treatment of dyspnea in endstage COPD, irrespective of ABG and PFT [100]. Ventilator settings then aim to improve patient comfort, alleviate dyspnea, and decrease air-trapping and work of breathing.

Nota bene: Recent German national guidelines for NIV $[10,11]$ also include the following items as indications for NIV in COPD:

- Nocturnal hypercapnia with a $\mathrm{PaCO}_{2}>55 \mathrm{~mm} \mathrm{Hg}$ (7.3 $\mathrm{kPa}$ ) irrespective of daytime $\mathrm{PaCO}_{2}$.

- Mild nocturnal hypercapnia (46-50 mm Hg; 6.1-6.7 $\mathrm{kPa})$ and an increase in $\mathrm{PtcCO}_{2} \geq 10 \mathrm{~mm} \mathrm{Hg}(1.3 \mathrm{kPa})$ during sleep.

It is the opinion of the SIG that these indications are not sufficiently evidence-based to be recommended presently and require further evaluation.

\subsection{Ventilator Settings}

The use of PSV-ST and an IPAP of at least $18 \mathrm{~cm} \mathrm{H}_{2} \mathrm{O}$ is recommended [94], if tolerated. The use of a high BURR is a component of the "high intensity ventilation" strategy recommended by German guidelines [84, 85]. However, in a British 3-month randomized trial of "high pressure and high BURR" (IPAP $29 \mathrm{~cm} \mathrm{H}_{2} \mathrm{O}, \mathrm{BURR}$ : resting respiratory rate -2 ) versus "high pressure and low BURR (BURR: 6/min)" in 12 severe hypercapnic COPD, the high BURR component did not provide any additional benefit on $\mathrm{ABG}$, nocturnal $\mathrm{PtcCO}_{2}$, or average daily use of NIV, raising a doubt as to the necessity of a high BURR [86]. Short rise times (Fig. 2, top; $100-150 \mathrm{~ms}$ ) are suggested to improve patient comfort and decrease work of breathing. Cycling criterion (Fig. 3, top) should be set at a high percentage of PIF, to allow time for expiration. As previously mentioned, several German studies have emphasized the benefit of high levels of pressure support ("high intensity NIV") on PFT, symptoms, and correction of ABG [84-86]. Values of pressure support provided in the above-mentioned studies $[96,97,99]$, as well as those reported in patients treated in Switzerland [4, 24], are in an intermediate zone with a satisfactory control of ABG (see online supplement; i.e., IPAP values of 18-25 $\mathrm{cm} \mathrm{H}_{2} \mathrm{O}$ ). Values of PEEPi reported in stable severe COPD are in the $4-6 \mathrm{~cm}$ range $[101,102]$. For patients with very severe airway obstruction, marked hyperinflation or hypercapnia, higher values of PEEPi must be anticipated and EPAP values titrated accordingly (i.e., up to $10 \mathrm{~cm} \mathrm{H}_{2} \mathrm{O}$ ).

${ }^{1}$ The ERS task force suggests a threshold $\mathrm{PaCO}_{2}$ level of $6.7 \mathrm{kPa}(50 \mathrm{~mm} \mathrm{Hg})$.

Respiration 2020;99:867-902 881 
Because of the high proportion of patients with associated OSA among COPD recovering from an AEHRF [83], respiratory polygraphy or polysomnography with Ptc$\mathrm{CO}_{2}$ monitoring are recommended in these patients, and/ or titration of EPAP considering the possibility of associated OSA.

\subsection{Obstructive Lung Diseases Other Than COPD}

CHRF related to diffuse bronchiectasis (cystic fibrosis [CF]-related and non-CF related). There are no RCTs of long-term NIV for bronchiectases, whether CF-related or not. Diffuse bronchiectases are recognized as a historical indication for long-term ventilation [103]. Use of NIV in diffuse bronchiectases is however associated with a poor prognosis $[104,105]$. Uncontrolled data suggest that NIV may reduce symptoms and hospital admissions in CHRFrelated to bronchiectasis [106-108]. In both CF-related and non-CF-related bronchiectasis, NIV may be used as a bridge to transplantation [109], and/or as an adjunct to airway clearance techniques and exercise training. For CF patients, 2 Cochrane reviews mention a short-term benefit of NIV on airway clearance and ABG in uncontrolled studies but are inconclusive as to the impact on survival $[110,111]$.

Severe bronchiolitis obliterans as manifestation of pulmonary graft versus host disease after stem cell transplantation or as chronic lung allograft dysfunction after lung transplantation may lead to CHRF and require NIV, either as a palliative treatment or as a bridge to transplantation. For these indications, no formal recommendations can be established, and the decision of implementing NIV must be taken by expert centers within a multidisciplinary management.

NIV may also be indicated as an adjunct to pulmonary rehabilitation in severe COPD, either during exercise training, or at night [112-117] (see section on special situations, 7.2).

\section{Obesity-Hypoventilation Syndrome}

\subsection{General Comments}

OHS is defined as the association of obesity (BMI $\geq 30$ $\left.\mathrm{kg} / \mathrm{m}^{2}\right)$, and daytime hypercapnia $\left(\mathrm{PaCO}_{2} \geq 45 \mathrm{~mm} \mathrm{Hg}\right.$ $[6.0 \mathrm{kPa}])$, in the absence of any other restrictive or obstructive respiratory condition associated with alveolar hypoventilation [118]. OSA is present in $80-90 \%$ of cases and must therefore systematically be sought for as soon as clinically feasible. In the obese population, hypercapnia is associated with a worse prognosis (higher mortality, higher rate of hospital readmission) [119]. NIV improves $\mathrm{ABG}$, quality of sleep, and reduces risk of hospital readmission $[120,121]$.

Recent RCTs have clarified the respective roles of NIV and CPAP in OHS [63, 122-125]. The most important data come from the Spanish multicentric Pickwick study and from Australian RCTs. In 2008, Piper et al. [123] randomized 36 moderately hypercapnic OHS patients to PSV versus CPAP: after 3 months there was no significant difference between groups as to improvement in ABG, $\mathrm{HCO}_{3}$, compliance, Epworth Sleepiness Scale (ESS), or HRQoL. However, patients with a daytime $\mathrm{PaCO}_{2}>55$ $\mathrm{mm} \mathrm{Hg}(7.3 \mathrm{kPa})$ and those with a nocturnal increase in $\mathrm{PtcCO}_{2}$ or important nocturnal hypoxemia had been excluded from this trial.

A short-term RCT showed that NIV improved ABG and SRBD in OHS [126]. It also improved respiratory drive [127].

The Pickwick study randomized 86 OHS patients (mean $\mathrm{PaCO}_{2} 49 \mathrm{~mm} \mathrm{Hg}$ [6.5 kPa]) without severe OSA to NIV (volume-assured PSV) versus usual care [124]. After 2 months, NIV was superior to usual care for control of $\mathrm{PaCO}_{2}, \mathrm{HCO}_{3}$, daytime sleepiness, and HRQoL.

The same multicentric Spanish group randomized 221 patients with OHS (BMI: $44 \pm 7 \mathrm{~kg} / \mathrm{m}^{2}$; mean $\mathrm{PaCO}_{2}: 50$ $\mathrm{mm} \mathrm{Hg}[6.7 \mathrm{kPa}])$ and severe OSA in 3 groups: NIV, CPAP, and usual care [63]. After 2 months, NIV provided a marginal benefit when compared to CPAP in terms of $\mathrm{PaCO}_{2}$ and $\mathrm{HCO}_{3}$, while both NIV and CPAP were superior to usual care. 6 min walking distance and $\mathrm{FEV}_{1}$ improved only in the NIV group. A substantial proportion of stable patients with OHS and OSA normalized their ABG $\left(\mathrm{PaCO}_{2}\right)$ when treated by $\mathrm{CPAP}$ alone and benefit was related to compliance.

An important contribution was the Australian study by Howard et al. [122]. These authors randomized 57 patients with OHS (mean age: 54 years, mean BMI: $54.9 \mathrm{~kg}$ / $\mathrm{m}^{2} ; \mathrm{PaCO}_{2}: 59.6 \pm 13.8 \mathrm{~mm} \mathrm{Hg}[7.9 \pm 1.8 \mathrm{kPa}]$; AHI: 82 $\pm 45 / \mathrm{h}$ ) to CPAP versus PSV: there was no difference in treatment failure (i.e., non-resolution or progression of hypercapnia) after 3 months. The most recent data from the Spanish Sleep Network group provide results of a long-term follow-up of 204 patients with OHS and severe OSA (average BMI: $43 \mathrm{~kg} / \mathrm{m}^{2}$; baseline $\mathrm{PaCO}_{2}: 60 \mathrm{~mm} \mathrm{Hg}$ [8 kPa]; AHI: 68/h) followed for a median of 5 years, randomized to volume-assured PSV versus CPAP: there was no difference between groups in terms of correction of ABG, number of hospitalization days or admissions, cardiovascular events, systemic blood pressure, or survival 
Fig. 8. Noninvasive ventilation (NIV) in obesity-hypoventilation syndrome. Suggested algorithm. PSV, bi-level positive pressure ventilation; OSAHS, obstructive sleep apnea hypopnea syndrome; AHI, apnea-hypopnea index. See text for explanation.

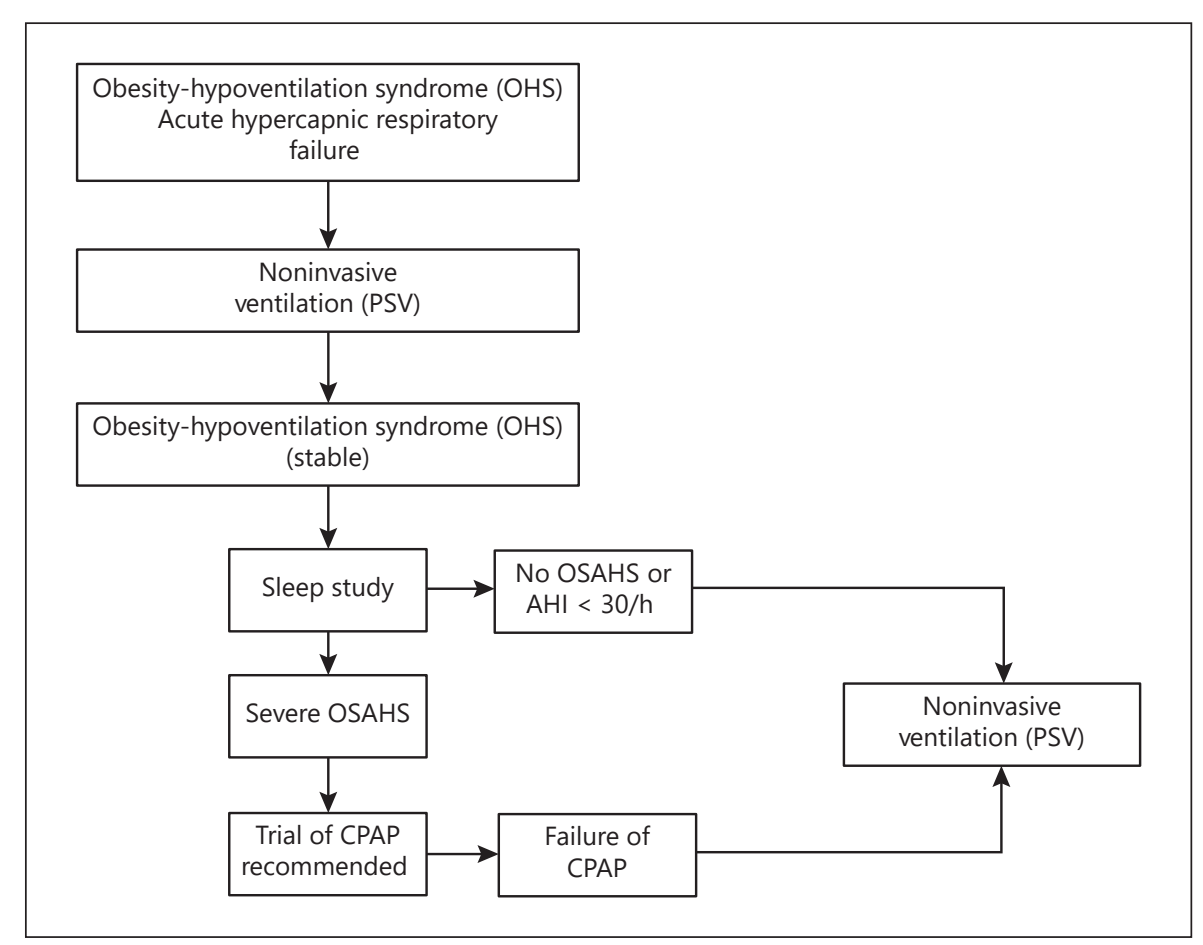

[125]. Therefore, it appears clearly that NIV is not always mandatory in stable OHS with associated severe OSA, and that these patients warrant a trial of CPAP. A recent consensus statement has been published by the American Thoracic Society [128].

Based on this evidence, the SIG suggests the following recommendations (Fig. 8):

- For all OHS patients with an AEHRF, NIV is the recommended therapeutic option.

- Within 3 months of an AEHRF attributed to OHS, a native sleep study should be considered. In the presence of severe OSA, a trial of CPAP is appropriate. In case of mild/moderate or no OSA, pursuit of NIV is recommended.

- For stable patients, when $A B G$ confirm the clinical suspicion of OHS, a sleep study is performed. An initial trial of CPAP is recommended if severe OSA is present (Fig. 8).

- For stable patients on long-term NIV for OHS, a switch to CPAP may be considered after documentation of presence of severe OSA.

In case of major weight loss (e.g., after successful bariatric surgery), the indication for CPAP or NIV must be reevaluated: in some cases (but not all) nocturnal positive pressure treatment may be discontinued $[129,130]$. It is mandatory that these patients be monitored on a regular basis (e.g., yearly) because of the possibility of partial or complete failure of bariatric surgery over time, with recurrence of OHS/OSA $[131,132]$.

As mentioned in the general comments, OHS patients are frequently comorbid, and management of comorbidities, screening for concomitant heart disease, integration in a weight loss program and/or orientation towards bariatric surgery, and rehabilitation are all important components of the management of these patients [133136].

\subsection{Ventilator Settings and Persistent Hypoxemia}

The American Association of Sleep Medicine (AASM) and several other groups recommend the systematic use of PSG (polysomnography) for titration of NIV in OHS [137]. This is however not realistic in most countries, because of the restricted availability of PSG and, sometimes, the lack of expertise of sleep centers in NIV titration [138]. The SIG does not consider PSG as mandatory for titration of NIV. Titration of NIV with PSG may reduce patient-ventilator asynchrony but does not impact on quality of sleep, ABG, or somnolence [139]. PSG or polygraphy are however mandatory for diagnosing and quantifying associated OSA. Use of transcutaneous capnogra- 
phy, whenever available, allows simultaneous assessment of the severity of nocturnal hypoventilation.

Once on positive pressure ventilation, a reasonable agreement between PSG and ventilator software determination of residual respiratory events has been documented in OHS (although in a limited number of subjects, and with devices from only one manufacturer) and thus, in clinical practice, ODI and ventilator software AHI can be used to control ventilator settings in combination with arterial blood gas analyses [66, 140, 141]. If ODI and AHI provided by ventilator software provide discordant results, a polygraphy or PSG may be contributive to a better documentation of residual respiratory events. Relying on ventilator-provided AHI alone is not recommended: nocturnal pulse oximetry should be combined with analysis of ventilator software [66].

Default devices for OHS are PSV ventilators. Although some groups use an "S" mode as a default option [123], the SIG recommends an S/T mode (spontaneous/timed), with a BURR close to spontaneous RR or slightly above. Use of a spontaneous (S) mode in OHS may increase occurrence of central apneas or hypopneas [142]. Conversely, a high BURR is associated with a better control of both central and obstructive residual events [142]. Some groups recommend PCV in severe OHS.

EPAP must be titrated to:

- control associated sleep-disordered breathing,

- improve V/Q relationships and nocturnal $\mathrm{SpO}_{2}$, and

- compensate for auto-PEEP which is also reported in OHS (due to closure of peripheral airways, reduced FRC and increased closing volume) [143-147].

Rise time should be preferably in the $150-250 \mathrm{~ms}$ range. Cycling criterion should favor a prolonged inspiratory pressurization to improve the V/Q ratio and thus oxygenation (i.e., low percentage of PIF; Fig. 3, bottom).

Persistent hypoxemia under NIV is an adverse prognostic sign [148]. Therefore, pressure support aims to control not only daytime $\mathrm{PaCO}_{2}$ but also nocturnal Ptc$\mathrm{CO}_{2}$ and $\mathrm{SpO}_{2}$. Levels of EPAP and IPAP should be increased as much as tolerated before adding oxygen on the ventilator circuit. If $\mathrm{PtcCO}_{2}$ is controlled, as well as $\mathrm{AHI}$, but $\mathrm{SpO}_{2}$ remains low, addition of oxygen on ventilator circuit may be considered [149]. There is no evidence that this impacts on outcome, but it does not affect $\mathrm{PaCO}_{2}$ and optimizing nocturnal $\mathrm{SpO}_{2}$ is a goal of NIV in all indications, mainly as a prevention of pulmonary hypertension and cor pulmonale [149]. Worsening of hypoxemia under NIV related to right to left shunt through a patent foramen ovale has been reported [150]. Conversely, NIV, when effective on ABG and nocturnal
$\mathrm{SpO}_{2}$, has a positive impact on pulmonary hypertension and LVEF [151].

For patients already familiar with CPAP (failures of CPAP), or patients diagnosed in a stable clinical state, initiating NIV on an outpatient basis is feasible and currently performed routinely by many centers or private practitioners [4].

Persistence of obstructive events may result from either inappropriate settings (too low EPAP) or from the use of facial versus nasal masks $[25,152]$. Several reports have documented that, for CPAP and NIV, facial masks may increase upper airway resistance by exerting a pressure on the mandibula, and thus compromise upper airway permeability. If obstructive events persist despite maximal EPAP tolerated and use of a nasal mask, increasing BURR has been shown to have a favorable impact on residual obstructive events [142].

The probability of daytime hypercapnia in OSA patients increases with BMI $[153,154]$. However, there is no established classification of the severity of OHS according to BMI. A classification of severity of OHS has been suggested based on daytime levels of $\mathrm{PaCO}_{2}$ in clinically stable patients (46-50 mm Hg [6.1-6.7 kPa]: mild; 51-55 $\mathrm{mm} \mathrm{Hg}$ [6.8-7.3 kPa]: moderate; $\geq 56 \mathrm{~mm} \mathrm{Hg}$ [7.5 kPa]: severe) [155]. In this retrospective study, the probability of controlling daytime $\mathrm{PaCO}_{2}$ with CPAP decreased as severity of OHS increased. There was no mention however of whether failure of PSV could be predicted according to severity of daytime hypercapnia. Pragmatically, although not formally established, probability of failure of PSV appears higher in super obese subjects (defined as having a $B M I \geq 50 \mathrm{~kg} / \mathrm{m}^{2}$ ). In this case, PCV or volumetric ventilation with PEEP may be required. Auto-adjusting PSV modes have not been shown to be superior to PSV-ST in "super-obese" subjects [33].

\section{Restrictive Respiratory Diseases Other Than Obesity-Hypoventilation and NMD}

Restrictive respiratory diseases (RLD) can be subdivided according to the major underlying physio-pathological disorder:

- RLD related to predominantly CWD, for example: kyphoscoliosis or other major chest wall deformities, ankylosing spondylitis, sequelae of chest trauma, or major chest surgery.

- RLD related to mixed diseases, for example: sequelae of collapsotherapy - including thoracoplasty - for tuberculosis (presently mainly of historical interest). 
- RLD related to predominantly parenchymal diseases: end-stage interstitial lung diseases (e.g., sarcoidosis, usual interstitial pneumonitis, hypersensitivity pneumonitis, pneumoconiosis), lung cancer (primary or metastatic) with or without lymphangitic carcinomatosis. These entities lead to:

- A decrease in compliance of the respiratory system.

- An increased work of breathing, and impaired respiratory mechanics (geometric changes with a negative impact on respiratory muscle function) in the case of CWD.

- A variable impact on gas exchange, with, in the case of end-stage parenchymal diseases, frequently severe hypoxemia.

- In some cases, a decrease in ventilatory response to $\mathrm{CO}_{2}$ [156].

There are no published RCTs for most of the disease groups mentioned above. Indication for NIV is based on observational studies $[15,157]$ showing a positive impact of NIV on HRQoL, hospital admissions, prevention of respiratory failure, endurance performance, and pulmonary hemodynamics [157-167].

$C W D$ is a recognized indication for NIV: the natural history of the disease, depending on the severity of the chest wall deformity, is a progression towards CHRF with dyspnea on exertion, then resting dyspnea, hypoxemia (related to V/Q mismatch and zones of atelectasis), and pulmonary hypertension leading to cor pulmonale [168]. Nocturnal hypoventilation precedes daytime hypercapnia, can be detected by $\mathrm{PtcCO}_{2}$, and is a prognostic factor for requirement of NIV within the following year [166]. NIV has been shown to be superior to LTOT in CWD, and is associated with an improved survival $[169,170]$. Other studies have shown improvements in ABG, PFT, and HRQoL. There have been no new recommendations since the 1999 ACCP expert-based consensus statement [15].

The SIG recommends initiating long-term NIV for restrictive lung diseases in the presence of symptoms of hypercapnia (fatigue, dyspnea, morning headaches...) and at least one of the following physiological criteria:

Daytime hypercapnia $\left(\mathrm{PaCO}_{2} \geq 45 \mathrm{~mm} \mathrm{Hg}\right.$ [6 kPa])

Nocturnal hypoventilation according to AASM criteria, defined by Berry et al. [77]:

- $\mathrm{PtcCO}_{2} \geq 55 \mathrm{~mm} \mathrm{Hg}$ (7.3 kPa) for more than $10 \mathrm{~min}$ or

- An increase in $\mathrm{PtcCO}_{2} \geq 10 \mathrm{~mm} \mathrm{Hg}(1.3 \mathrm{kPa})$ compared to awake supine value to a value exceeding 50 $\mathrm{mm} \mathrm{Hg}(6.7 \mathrm{kPa})$ for more than $10 \mathrm{~min}$.
Nota bene. The criterion " $\mathrm{SpO}_{2}<88 \%$ for more than 5 min on nocturnal pulse-oximetry" mentioned in the 1999 consensus statement has been deleted, because of its lack of specificity, and the increasing availability of $\mathrm{PtcCO}_{2}$ recordings.

\subsection{Ventilator Settings}

PSV in an S/T mode is the default approach. Values of EPAP are low, unless OSA is associated. Rise time should be preferably in the 150-250 ms range. Cycling criterion should be set to a low percentage of PIF (Fig. 3, bottom) to counteract the rapid decrease in inspiratory flow secondary to diminished chest compliance. Illustrative settings are provided in the online supplementary material.

Severe decreases in chest wall and/or parenchymal compliance may require high levels of pressure support over time, and use of PCV or volume-cycled devices as CRF progresses must be considered. In some cases, if quality of life is preserved, invasive ventilation may be considered.

Pulmonary rehabilitation has been reported as an efficient adjunct to long-term NIV in CWD [171].

\section{Neuromuscular Disorders}

\subsection{General Comments and Caveats}

- Neuromuscular disorders are a very heterogenous group of diseases, with a variable prognosis (see Table 4 for most frequent indications for NIV in NMD). Each NMD has its own "agenda" as to the timing of the expected progression towards CHRF. Furthermore, within each NMD, this "agenda" is variable from case to case. Follow-up before NIV must be adapted accordingly.

- Dyspnea, and daytime hypercapnia are late events in the evolution of most NMD. Classical signs of respiratory failure such as tachypnea, recruitment of accessory muscles, or "tirage" may be masked by the underlying neuromuscular impairment. NIV must be implemented if possible before occurrence of daytime hypercapnia to prevent acute episodes of hypercapnic failure.

- Many NMD have systemic implications (cardiologic, digestive, endocrinologic, orthopedic...), and regular assessment by a multidisciplinary expert team is important. The frequency of follow-up consultations depends on the underlying disorder. Multidisciplinary management has been shown to im- 
Table 4. Most frequent neuromuscular disorders associated with chronic alveolar hypoventilation

Myopathies and muscular dystrophies:

- Duchenne's muscular dystrophy and Becker's muscular dystrophy

- Myotonic muscular dystrophy (Steinert's diseases)

- Limb girdle muscular dystrophy

- Congenital muscular dystrophies

- Metabolic myopathies (e.g., McArdle, Pompe, mitochondrial myopathies)

- Inflammatory myopathies (e.g., polymyositis/dermatomyositis)

Diseases of the muscular endplate

- Myasthenia gravis

- $\quad$ Paraneoplastic syndromes (e.g., Lambert-Eaton syndrome)

Motoneuron disorders

- Motoneuron diseases (e.g., Amyotrophic lateral sclerosis, Spinal muscular atrophies (type I-IV)

- Poliomyelitis and post-poliomyelitis syndrome

Diseases of brain stem and/or pyramidal tract

- Congenital or acquired central hypoventilation (Ondine's syndrome)

- Traumatic spinal cord lesions

- Arnold-Chiari malformation and associated conditions

- Multiple sclerosis

Polyneuropathies

- Post-ICU critical illness polyneuropathy and myopathy

- Inflammatory neuropathies (e.g., Guillain-Barré)

- Phrenic neuropathies

- Other axonal neuropathies (toxic or paraneoplastic)

This list does not provide all possible neuromuscular indications for NIV.

prove prognosis per se in motoneuron diseases [172-174]. Advanced care planning should be a component of multidisciplinary management in all NMD, and especially in rapidly progressive disorders such as ALS.

- Treating NMD patients with NIV has socioeconomic implications and represents a high burden on families and caregivers. It is part of the management of these patients to ensure that they receive appropriate support by experienced social workers, that requests for devices such as (electric) wheel chairs, or communication devices are made in a timely fashion, and that home support is ensured so as to relieve the burden on families. The authors underline that management and home support of NMD patients should be improved in Switzerland and that appropriate funding should be provided and assured.
- Many NMD become clinically apparent in childhood or at adolescence, and patients and their families often have a multidisciplinary management follow-up by a pediatric team. Progressive and coordinated transition to the adult multidisciplinary disease management team must be carefully planned.

- In ALS, multidisciplinary management is associated with optimized timing of NIV. Even selected patients with bulbar dysfunction can derive benefit from NIV [175].

- Most of the evidence concerning NIV in NMD is based on observational studies [3,104, 105, 165], albeit for ALS, for which an RCT with a small number of participants clearly showed that NIV improved HRQoL and survival in non-bulbar patients [176]. The fact that HRQoL does not deteriorate in patients with Duchenne muscular dystrophy after initiation of NIV was also demonstrated by Kohler et al. [177].

\subsection{Follow-Up before Implementing NIV}

- For all patients with NMD and a probability of evolution towards hypercapnic respiratory failure, a regular follow-up is mandatory and should include clinical assessment, targeted medical history, spirometry, vital capacity sitting and supine, sniff nasal inspiratory pressure and maximal inspiratory pressure, cough peak flow, nocturnal pulse oximetry (or whenever possible, nocturnal $\mathrm{PtcCO}_{2}$ ), and daytime ABG. Nocturnal hypoventilation is predictive of requirement for NIV within the following months [166].

- Criteria proposed as threshold levels for implementing NIV are variable according to the underlying disease. Also, agreement between different criteria is often moderate or poor. Most tests used for follow-up of respiratory function are collaboration-dependent; their course over time may differ from one test to another [178, 179]. Bulbar dysfunction may also impair reproducibility of respiratory function tests. A panel offunctional tests performed at regular intervals is therefore preferable to appreciate the degree of respiratory muscle impairment $[20,180]$.

- Frequency of follow-up depends on the underlying disorder and its expected progression (usually between 3 months and 1 year). 
The SIG considers as clinical indications for NIV in NMD the following items:

- Control of symptoms related to respiratory muscle weakness and/or sleep-related hypoventilation or SRBD are per se an indication for NIV (e.g., morning headaches and fatigue, orthopnea, resting dyspnea, severe recruitment of accessory muscles, unexplained weight loss), even in the absence of daytime hypercapnia [181-183].

- Presence of sleep-disordered breathing (especially OSA) represents an increase in work of breathing, irrespective of symptoms, and NIV (because these patients will progress to CHRF) or CPAP should be considered.

Any one of the following are physiological indications for NIV in NMD:

- Daytime hypercapnia $\left(\mathrm{PaCO}_{2} \geq 45 \mathrm{~mm} \mathrm{Hg}\right.$ [6 kPa]) or

- Daytime normocapnia with nocturnal hypoventilation measured by $\mathrm{PtcCO}_{2}$ according to AASM criteria (because of a high risk of rapid progression to daytime hypercapnia):

$\mathrm{PtcCO}_{2} \geq 55 \mathrm{~mm} \mathrm{Hg}(7.3 \mathrm{kPa})$ for more than $10 \mathrm{~min}$ or

An increase in $\mathrm{PtcCO}_{2} \geq 10 \mathrm{~mm} \mathrm{Hg}(1.3 \mathrm{kPa})$ compared to awake supine value to a value exceeding 50 $\mathrm{mm} \mathrm{Hg}(6.7 \mathrm{kPa})$ for more than $10 \mathrm{~min}$.

- Vital capacity $<50 \%$ of predicted or sniff nasal inspiratory pressure/maximal inspiratory pressure $<40$ $\mathrm{cm} \mathrm{H}_{2} \mathrm{O}$, especially in rapidly progressive NMD.

Comment: Metabolic alkalosis should suggest the possibility of nocturnal hypoventilation and should lead to specific investigations. Also, prevalence of nocturnal hypoventilation varies widely according to definitions provided [78].

\subsection{Ventilator Settings}

- Some expert centers consider that NIV in NMD should be preferentially performed with volume-cycled devices, and with alarms, because of the risk of prolonged central sleep apnea or hypopnea, and for the security of the patient. Over the past decades, however, there has been a drift towards the use of PSV in S/T mode as default approach, at least as an initial modality (see section on highly dependent patients). Life support devices provide all the necessary alarms for patient safety.

- In most NMD, compliance of the respiratory system is marginally affected if chest wall deformity is not severe and pressure support levels are generally low.
- EPAP values may become a factor of discomfort when respiratory muscles are severely affected, and should be kept at minimal values in the absence of SRBD.

- Inspiratory trigger settings may require adjustment (increase in sensitivity) as disease progresses.

- An " $\mathrm{S}$ " mode is not recommended as standard setting, but can be used for special situations (i.e., eating with NIV, mouthpiece ventilation). An S/T mode with a BURR close or slightly above spontaneous RR is standard. The authors suggest to titrate BURR so as to minimize percentage of cycles triggered by the patient, and thus minimize residual work of breathing (i.e., "capture" the patients' spontaneous RR).

- Rise time is set according to patient comfort, usually 150-250 ms. Higher values will significantly impinge on pressurization and should be used only exceptionally.

- It is an unexplained but frequent observation that patients with NMD are often more comfortable when slightly hyperventilated.

- Patient-ventilator asynchrony may occur in NMD (mostly in motoneuron disease) as a consequence of paradoxical movements of the vocal cords which may compromise the efficacy of ventilation [184]. Strategies to adapt ventilator settings have been proposed [25].

- Adjunction of oxygen is seldom required in the absence of any underlying lung disorder.

- For many NMD, use of NIV will become necessary outside of the home (i.e., adapted to an electric wheel chair), requiring a built-in battery with prolonged autonomy; also, use of interfaces such as mouthpieces may be useful: in this case, multimodal ventilators with performant built-in batteries and specific modes for mouthpiece ventilation are recommended [185]. When dependence to NIV reaches $16 \mathrm{~h}$ /day, having a back-up "life support-type" ventilator (i.e., a second device) is mandatory.

\subsection{Interfaces in NMD}

- Mouthpiece ventilation must be considered in very dependent patients to facilitate speech and social contacts, and to provide ventilator support while on the move (electric wheelchair). Several ventilators presently provide a "mouthpiece" mode which facilitates implementation of mouthpiece ventilation [185].

- Use of nasal pillows may also increase comfort during the daytime. 
- Although there is a theoretical risk of aspiration when using facial masks in patients who cannot easily remove their interface, in clinical practice, facial masks are often the only way to control the frequently occurring mouth leaks, and are therefore used regularly (56\% of NMD cases in the GLS study) [4]. Auxiliary means to facilitate the removal of the mask by the patient (e.g., hand strap) should be then considered. The alternative - use of a chin strap and nasal mask - is a possible option.

- In 24-h NIV dependency, a common approach is to use an oro-nasal/face mask during sleep and nasal pillows or a nasal mask during daytime.

\subsection{Mechanical Insufflation/Exsufflation in NMD}

Assessment of ability to cough must be performed systematically in all patients with NMD, and, if necessary, specific treatment must be implemented.

MIE devices provide a mechanical assistance for patients with an impaired ability to cough. These devices can be used with a facial mask, a mouthpiece, or a tracheostomy cannula, in children or adults. With appropriate teaching, these devices can be used by non-professional caregivers, or sometimes by the patient alone. Training is usually provided at home or at the hospital/specialized center by experienced physiotherapists or respiratory therapists/nurses. Illustrative video supports can be easily downloaded from the internet, although they do not replace appropriate individualized training.

Basically, MIE simulates the physiological cough process by providing 3 phases: (a) an insufflation phase to increase lung capacity as close as possible to TLC and benefit from the elastic recoil of the respiratory system; (b) an inspiratory plateau which may be provided manually (to improve synchronization) or automated (to facilitate home treatment by non-professional caregivers); (c) an exsufflation phase: a negative pressure is applied to the airways, which, combined with the elastic recoil pressure of the respiratory system, generates an expiratory flow which mobilizes secretions. Use of MIE can be combined with manually assisted cough techniques to improve efficacy [186, 187].

Nota bene. These recommendations will not describe techniques such as "glosso-pharyngeal breathing," "airstacking," manually assisted coughing or other techniques to assist airway clearance. These techniques are part of the standard management of secretions and airway clearance in severe NMD $[188,189]$.
The SIG suggests the following recommendations for implementing the use of MIE (Fig. 9):

In all cases, clinical assessment is mandatory, and MIE devices may be considered as necessary irrespective of cough peak flow values.

The indication for MIE is based on the inability to clear secretions in an effective manner (clinical assessment) and measurements of the cough peak flow:

$270 \mathrm{~L} / \mathrm{min}$ : cough is probably efficient.

160-270 L/min: cough may be inefficient; it is mandatory to instruct the patient and caregivers on appropriate assisted cough techniques and, if they fail, to evaluate MIE devices.

$<160 \mathrm{~L} / \mathrm{min}$ : spontaneous cough is most probably inefficient to clear secretions from the airways, and the use of assisted cough techniques is mandatory. If they fail or are not feasible, MIE devices are necessary.

Use of MIE should be encouraged on an outpatient basis in all patients with NMD, a decreased cough peak flow, and difficulties to clear their airways from secretions with assisted cough techniques.

Training at home can be provided to caregivers and/or unexperienced healthcare workers by experienced physiotherapists or respiratory therapists. Repeated interventions for caregiver education may be necessary.

MIE settings. A recent report from an expert center (Royal Brompton Hospital, UK) provided average settings for MIE from 181 patients with NMD (130 adults, 51 children; 156 with NIV, 8 with a tracheostomy) as well as an algorithm for establishing MIE settings [190]. Values reported for adults were (median; IQR): $28 \mathrm{~cm} \mathrm{H}_{2} \mathrm{O}$ (25-30) for insufflation; $-35 \mathrm{~cm} \mathrm{H}_{2} \mathrm{O}(-32 ;-40)$ for exsufflation; TI: $1.5 \mathrm{~s}$ (1.3-1.8); expiratory time: $2.0 \mathrm{~s}$ (1.5-2.4); pause: $1.5 \mathrm{~s}(1.3-2.0)$. Most patients used automated modes. Rarely, higher pressures may be required, when compliance of the respiratory system is markedly decreased (severe obesity, kyphoscoliosis), or in patients with a tracheostomy and a small canula, to overcome the additional airway resistance. Initiation is usually performed with lower insufflation pressures $(15--20 \mathrm{~cm}$ $\mathrm{H}_{2} \mathrm{O}$ ). Pressures are then increased gradually beginning with exsufflation pressures [186, 187].

In motoneuron disease, paradoxical movements of the vocal cords and closure of upper airways (adduction of aryepiglottic folds, retroflex movement of the epiglottis, closure of hypopharynx, backward movement of the tongue) during MIE may compromise its efficacy and require adapting (decreasing) pressure levels and using a manual mode [191]. This does not only occur in bulbar 
Fig. 9. Threshold levels for cough peak expiratory flow for implementing mechanical insufflation/exsufflation. This must be combined with clinical evaluation of cough efficacy.

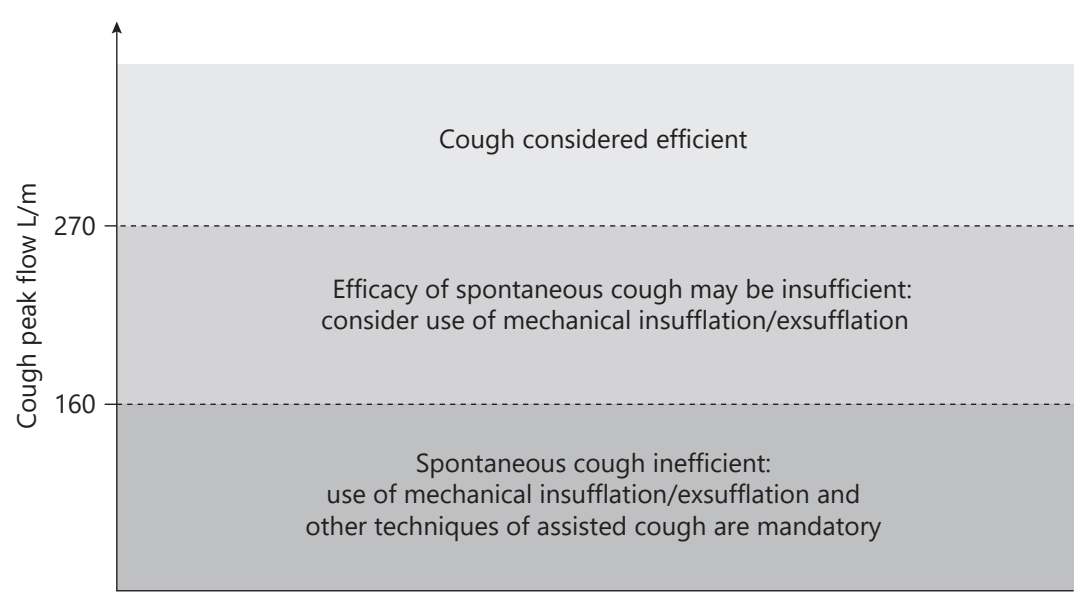

Management of airway secretions according to Cough Peak Flow onset patients. Susceptibility to MIE settings may also change over time. Inspiratory values are critical: in patients with motoneuron disease, higher cough peak flow values were obtained using insufflation pressures of 30 versus $40 \mathrm{~cm} \mathrm{H}_{2} \mathrm{O}$ [192]. Insufflation values may have to be decreased to $15 \mathrm{~cm} \mathrm{H}_{2} \mathrm{O}$, with asymmetrical settings for insufflation and exsufflation (i.e., maintaining higher exsufflation than insufflation pressures) [191]. Decreasing insufflation pressures and flow combined with longer TIs may improve upper airway stability in these cases [193]. Triggering insufflation by the patient may also be effective to reduce closure of the upper airway. In experienced centers, these events can be detected by transnasal video laryngoscopy $[184,191,193,194]$.

Patient information. An application for cell phones and tablets (Apple or Android) developed by the Geneva CeSLA team is available as freeware for ALS patients and caregivers (CeSLApp).

\section{Sleep-Related Breathing Disorders}

\subsection{General Comments}

For most SRBD, positive pressure treatment is provided either with CPAP, or adaptive servo-ventilation (ASV) $[5,195,196]$.

SRBD is the 1st indication for NIV in the French ANTADIR observatory (www.antadir.org; ASV not included). Conversely, in the GLS study, patients with SRBD represent only $9 \%$ of patients under NIV.

\subsection{Indications}

The SIG recommends NIV for SRBD in the following situations:

- OSA and failure of CPAP because of persistence of abnormal AHI/RDI/ODI, and/or poor tolerance and/or requirement of high pressures to control respiratory events. In this indication, NIV can most often be implemented on an outpatient basis.

- Normo- or hypocapnic central sleep apnea. This includes Cheyne-Stokes breathing and other forms of periodic breathing. When CSA are either idiopathic, induced by medication (e.g., opiates), or associated with neurological disorders (most often cerebrovascular diseases), NIV using PSV-ST can be considered after failure of CPAP or ASV. ASV is slightly superior to PSV in opiate-induced CSA [197] and is more appropriate to avoid hyperventilating these patients, which could aggravate the underlying SRBD.

- Hypercapnic central sleep apnea. This group includes CSA induced by medication (e.g., opiates) or associated with neurodegenerative diseases. In these settings, titration of NIV must be monitored by respiratory polygraphy or polysomnography, with transcutaneous capnography. In certain NMD (namely $A L S)$, care must be taken to avoid or control paradoxical movements of vocal cords [25].

In case of cardiac dysfunction (LVEF $\leq 45 \%)$ and Cheyne-Stokes breathing, ASV is contra-indicated. Alternative treatments must be discussed after optimiza- 
tion of medical treatment of chronic heart failure (fixed pressure $n C P A P$, oxygen...) [198]. There is, however, no evidence against the use of NIV in this setting in hypercapnic patients.

\section{Special Situations}

\subsection{The Highly Dependent Patient}

A small group of patients under long-term NIV will become severely or totally dependent of their ventilator support. In the recent GLS survey, 2\% of all NIV patients used their ventilator more than $16 \mathrm{~h} /$ day. These patients have most often advanced NMD (ALS, Duchenne muscular dystrophy...), very severe COPD or other causes of tetraplegia (post traumatic or not).

The SIG group raises several issues of concern.

(1) Security. Because an interruption of ventilator support for a few minutes or hours may in some cases be fatal, having at home one spare ventilator ready to use, plugged and charged, with the same settings, is mandatory. Both ventilators must belong to the "Life support" category of home ventilators.

The French guidelines published by the "Haute Autorité de Santé" (November 2012) recommend that all patients requiring the use of their ventilator for more than $16 \mathrm{~h} /$ day be equipped with two "life support" home ventilators. This is also the case in the German national guidelines for HMV [12] and is the usual practice of British and Belgian centers.

The SIG authors recommend that a second (back-up) ventilator should be provided when daily use of NIV exceeds 16 h/day because:

- Minor changes in respiratory status (i.e., lower or upper respiratory tract infection) can lead to total dependence in a matter of hours or days.

- Not having a second device available in this context can be a major risk in areas where rapid intervention at home is not available.

- Conversely, a second device is the best way to avoid unnecessary admissions to an emergency ward for purely technical reasons.

- Evolution towards a complete dependence on NIV is a matter of weeks or, at most, months in these patients. Importantly, the second ventilator is contributive to improving the autonomy of the patient since it can be used for mouthpiece ventilation and/or on an electric wheelchair and/or in a separate part of the home.
(2) Autonomy. As mentioned above, use of a second ventilator allows having a device for an electric wheelchair, and/or for use with a mouthpiece, and/or for travelling. This can also be required in a home with stairs.

(3) Appropriate home support. For highly dependent patients, the NIV team must ensure that appropriate support is provided to caregivers, and that adaptations of home environment are organized when necessary. These patients usually require 24/24-h support 7 days/week, and financial support as well as trained care givers must be made available, irrespective of the financial situation of the patient's family. Although this is the case in most EU countries, the financing of this support is not guaranteed in Switzerland, and funding must often be sought for via patient associations, or private foundations (e.g., Pro Infirmis).

In case of a medical or technical problem, a hotline must be available for the patient's care givers and advance care directives must have been discussed and clarified.

For patients travelling abroad - which is possible for severely dependent NMD patients for instance if appropriately planned - temporary allocation of an additional back-up ventilator may increase level of security when confronted to another health system and different healthcare providers. Local reference "hotline" numbers must be provided in case of technical problems.

\subsection{NIV and Rehabilitation}

NIV has 2 documented indications in pulmonary rehabilitation. The first is to increase tolerance to exertion in severely limited patients (i.e., during or just after an ICU stay for acute exacerbation, or as a first step for a severely limited and bed-ridden patient). In this indication, NIV may allow bed-ridden subjects to walk, or perform exercises on cycloergometers, thus potentially accelerating their recovery, although this is not formally demonstrated $[115,164,199-205]$. This approach can also be provided at home for patients performing their exercises under supervision.

The second indication is as an add-on treatment, e.g. nocturnal NIV during a rehabilitation program, with benefits documented in hypercapnic COPD and ILD patients [206, 207].

NIV during exercise should be adapted by experienced chest therapists/physiotherapists according to patient comfort. Increasing pressure support is usually required, as well as EPAP to decrease dynamic hyperinflation in severe COPD [208]. Rise time and $\mathrm{TI}_{\mathrm{MIN}}$ must be adapted to the patient's increase in respiratory rate. 
Table 5. Comparison of invasive and non-invasive long-term home ventilation

\begin{tabular}{|c|c|c|}
\hline & Invasive ventilation & Non-invasive ventilation \\
\hline Advantages & $\begin{array}{l}\text { - Suctioning of lower airway secretions facilitated } \\
\text { - Cuff inflation provides some protection against aspiration of } \\
\text { secretions and foreign material } \\
\text { - Application of higher airway pressure feasible } \\
\text { - Quantitative monitoring of ventilation reliable } \\
\text { - Advanced alarm functions available }\end{array}$ & $\begin{array}{l}\text { - Non-invasive } \\
\text { - Convenient initiation and withdrawal, intermittent use } \\
\text { - Swallowing and speech not impaired } \\
\text { - Near-normal life when not on NIV, less stigmatization } \\
\text { - Independent usage }\end{array}$ \\
\hline Disadvantages & $\begin{array}{l}\text { - Invasive procedure required } \\
\text { - Risk of tracheomalacia, tracheal stenosis, and bleeding } \\
\text { - Stigmatization of patient in daily life } \\
\text { - Speech and swallowing may be impaired } \\
\text { - Higher risk of lower airway infection } \\
\text { - Limited care facilities available }\end{array}$ & $\begin{array}{l}\text { - Cooperation required } \\
\text { - Mask leaks common, in particular with high pressure support } \\
\text { - Risk of skin damage/pressure ulcers } \\
\text { - In patients requiring continuous or near-continuous ventilatory } \\
\text { support, eating/drinking is problematic } \\
\text { - Airways are not protected }\end{array}$ \\
\hline $\begin{array}{l}\text { Suggested } \\
\text { indications }\end{array}$ & $\begin{array}{l}\text { - Severe, life-threatening ventilatory failure } \\
\text { - Failure of NIV } \\
\text { - Continuous ventilatory support ( } 20 \mathrm{~h} / \text { day) needed and not } \\
\text { feasible via NIV } \\
\text { - Reliable alarms needed (life support) } \\
\text { - Severe bulbar dysfunction } \\
\text { - Fixed upper airway obstruction } \\
\text { - Severe hypersalivation and swallowing difficulties }\end{array}$ & $\begin{array}{l}\text { - Intermittent, non-life-sustaining support needed } \\
\text { - Sleep-disordered breathing }\end{array}$ \\
\hline
\end{tabular}

\subsection{NIV and Palliative Care}

NIV is a possible option in palliative care, for example, for patients with advanced oncologic disorders, progressive respiratory failure related to end-stage interstitial lung disease, or post stem-cell or solid organ bronchiolitis obliterans [209]. End-stage interstitial lung disease is often associated with severe dyspnea, and a major increase in work of breathing. Treatment, its timing, and settings are primarily symptom-based, and implementation must be performed by therapists experienced in NIV. Rate of failure of symptom control may be high [210, 211]. NIV must aim to improve symptom control, but not prolong unnecessary suffering or discomfort. Deciding when to withdraw NIV should be discussed with the patient and his/her close relatives before implementing NIV or invasive ventilation. In diseases leading to impaired communication (such as ALS), and potentially to a locked-in syndrome, it is particularly important to clarify beforehand when ventilator support should be interrupted [212,213].

Alternative treatments under clinical evaluation are high-flow, humidified oxygen, or CPAP.

\subsection{Invasive $H M V$}

7.4.1. Invasive Ventilation in Switzerland and Other Countries

Long-term positive pressure ventilation via tracheostomy (TPPV) remains a valuable option for a subgroup of specifically selected patients. In a European survey, patients treated with TPPV represented $13 \%$ of the population on long-term mechanical ventilation [82], with a wide variability from country to country. In a British study of all-cause mortality of 1,210 patients under HMV over a 10-year period, patients using TPPV represented $12 \%$ of the deceased [214]. A similar proportion of TPPV in HMV has been reported in Canada [215]. Detailed data of non-hospitalized patients on TPPV in Switzerland are not available but figures are probably much lower. Among 3,498 patients who started home ventilation between 2016 and 2019, 48 (1.4\%) patients were under TPPV (annual report, Schweizerischer Verband der Krankenkassen; SVK). In the GLS Study, 11 of the 500 patients under HMV (2.2\%) were under TPPV, a number which has remained stable over the past 20 years [4]. Patients with spinal cord injuries or chronic NMD who are $24 \mathrm{~h}$-ventilator-dependent represent the most important subpopulation on TPPV.

\subsubsection{Conditions in Which TPPV Is Used}

TPPV may be initiated following invasive mechanical ventilation in the ICU due to acute or acute-on-chronic respiratory failure with subsequent weaning failure. In NMD with bulbar dysfunction or massive secretions, elective tracheotomy may be an option. In some centers, TPPV is routinely initiated when patients with NMD 
such as Duchenne's muscular dystrophy (DMD) become ventilator dependent. However, 24-h NIV is also feasible and convenient for many DMD and other neuromuscular patients and is standard practice in many centers [216219]. The availability of NIV together with MIE (Cough assist) is likely to reduce the need for invasive ventilation.

In rapidly progressing NMD such as motor neuron disease with bulbar dysfunction, the question of TPPV arises often and requires careful consideration [213]. The final decision is the patient's, and a non-biased complete information to the patient and his/her caregivers should be provided well in advance. Items to be discussed include: expected burden for caregivers in case of 24-h home care, limited availability of nursing home beds, specific complications, possibility and modalities of withdrawal from invasive ventilation and end-of-life care. Some institutions have published their concept of TPPV in motor neuron disease [213]. Recommendations and patient decisions are influenced by personal, cultural, and ethical aspects, and informed decisions in terms of prognostic expectations as well as end-of-life-care should be made individually.

There is no robust evidence to support recommendations on indications of TPPV. However, Table 5 lists some points to be considered.

\subsubsection{Consequences of TPPV}

TPPV creates a major burden for caregivers in Switzerland because options for long-term care of ventilatordependent tracheotomized patients outside the hospital are limited and financial support for qualified help at home is often insufficient. Healthcare costs for patients with chronic respiratory failure are far higher for invasive than for non-invasive ventilation [220]. Management of patients on invasive ventilation usually requires $24-\mathrm{h}$ care. This burden is often left to the close family who has to be trained in tracheostomy care, airway clearance, and emergencies. Specific, formal lay person training programs exist for instance in France and Germany but not in Switzerland. Furthermore, long-term care institutions for this population are almost inexistent in Switzerland. However, for slowly progressive neuromuscular and chest wall disease, the Mathilde Escher Heim in Zurich is an example of a specialized care center where a large cohort of patients with muscular dystrophy or other NMD live and/or attend school and pursue a professional activity.

Quality of life on long-term TPPV, implemented after careful preparation, may be good in patients with muscular dystrophy or CWD $[177,221,222]$. It may however be severely impaired in patients with unscheduled tracheostomy after weaning failure in the ICU, for instance in COPD [223]. To improve quality of life, mobility is an important aspect for patients on TPPV. Therefore, 2 ventilators, of which one is portable or attached to an electrowheelchair should be available. These ventilators must have built-in batteries that allow a safe mobility for several hours.

TPPV is associated with the risk of specific complications such as life-threatening - although rare - tracheal bleeding, ventilator-associated pneumonia, obstructive mucus plugging or tracheal granuloma formation and stenosis that may increase morbidity and mortality compared to NIV [224-226]. Data on outcomes of long-term tracheostomy ventilation come from cohort studies but have not been systematically analyzed and compared to NIV in a conclusive way $[214,215,227,228]$.

\subsubsection{Practical Aspects}

In general, TPPV patients and patients with an anticipated ventilator dependency should be managed in a specialized tertiary center by a multidisciplinary team. A specific knowledge of circuits, cannulas, humidifiers, ventilators, speech functions, and TPPV-associated complications is mandatory. An overview on the topic has been published recently and is summarized here [23].

TPPV can be delivered via surgical tracheotomy or percutaneous dilatational tracheostomy (usually performed in the ICU). Both techniques have specific complications, that is, risk of instability during cannula exchange in the early phase and bleeding in case of percutaneous dilatational tracheostomy or an oversized lumen in case of surgical tracheotomy.

Cannula and cuff. Different cannula types are available (length, angle, diameter, flexible vs. rigid, with and without cuff, fenestrated vs. closed) [189]. The choice of the right tracheal cannula size and length is important to avoid leakage and damage to the trachea. Regular change of the outer tracheal cannula should be performed, at least initially, by an experienced team. Typical intervals are 6-8 weeks but depend on the amount of secretions and other aspects (e.g., local pain). A replacement tracheal cannula of the same size and of a smaller size should always be available. Inner cannulas are often changed several times a day. An inflated cuff reduces the risk of aspiration but cannot reliably protect from this complication. Conversely, an inflated cuff can cause pressure ulcers and compromise swallowing. It is recommended to apply a low cuff pressure that is periodically monitored, and to avoid permanent cuff inflation. 
A tracheotomy affects swallowing and speech. In the initiation phase of TPPV, intensive training of laryngeal function and speech training while the cuff is deflated are important. Some patients with preserved bulbar function may not need a cuffed tracheal cannula or require TPPV with an inflated cuff only during sleep.

When a cuff is inflated and seals the trachea properly, secretions cannot enter the lower airways. However, if patients cannot swallow secretions, they may accumulate above the cuff balloon. This results in desensitization of the cough reflex in the upper airway and larynx. A deflated cuff allows airflow towards the upper airway for speaking and coughing. It is important that the tracheal cannula chosen is thin enough to allow air passage to the upper airway while the cuff is deflated, especially during use of a one-way speech valve (Passy Muir ${ }^{\circledR}$ or similar valve). Application of a speech valve while the cuff is inflated can be life-threatening since only an inward flow is possible.

If a fenestrated cannula is used, both a closed and a fenestrated inner cannula must be available. When using the fenestrated inner cannula and a deflated cuff together with a speech valve, phonation is facilitated due to air flowing around the cannula and through the fenestration towards the larynx.

Circuits. Different circuits (single- vs. double-limb) are available for TPPV. Both a single-limb non-vented circuit with an exhalation valve (active circuit) or, less commonly, an intentional leak connector (passive circuit) and a double-limb circuit with separate inspiratory and expiratory limbs are available for TPPV [218]. Separate in- and expiratory limbs allow a reliable quantitative monitoring of VT, minute ventilation, and leaks. However, a single-limb circuit is easier to handle.

Ventilators. Different life-support ventilators are available for invasive HMV (online suppl. Table S1). As previously mentioned (section 7.1), 2 ventilators are mandatory for security reasons in highly dependent patients. Different settings for day- and night-time may be used. Pressure-controlled ventilation (PCV) or volume controlled ventilation are more commonly used than PSV in TPPV [214]. A target-volume might be set in addition to pressure modes, but advantages of this have not been demonstrated so far. Specific alarms are available for invasive ventilation with life-support ventilators. Noteworthy is the fact that VT and VE cannot be accurately measured when cuff is deflated (unintentional leak through upper airway): this impairs alarm functions.

Humidification. Heated humidification is standard in invasive HMV during the night to avoid desiccation of the airways and thus bleeding and obstruction with mucus plugs. However, humidification is seldom feasible in patients who are mobile in a wheel-chair: in this situation heat- and moisture-exchanging filters are sufficient in most cases.

Suctioning and mechanical in-/exsufflation. Suctioning of the upper and lower airways is routinely performed in TPPV. Deep suctioning should be limited because of the risk of mucosal lesions. Chest physiotherapy (assisted cough techniques) and mechanical in-/exsufflation with a Cough assist are important adjunctive measures to mobilize peripheral secretions towards the central airways.

7.4.5. Special Considerations in Spinal Cord Injuries Spinal cord injuries affect the respiratory system through several mechanisms [229-233]:

- Loss of control of respiratory muscles, even at low spinal cord injury levels (affecting pelvic and abdominal muscles).

- Decreased chest wall compliance, which can progress after the initial lesion.

- Altered central respiratory control and negative impact of frequently used CNS suppressants (antispasmodic and pain-relieving medications).

- Diaphragm dysfunction (e.g., "paradoxical orthopnea"), because of abdominal distention (chronic obstipation and intestinal dysautonomy) or increased intra-abdominal pressure (spasticity) $[234,235]$.

- Bronchial hyperreactivity in injuries above TH 6, due to sympathetic roots disconnection $[236,237]$.

- SRBD [238, 239].

- Impaired clearance of airway secretions.

Requirement for ventilatory support. For lesions at a level of C3 or above, initial invasive mechanical ventilation is almost invariably required. A change to electrostimulation of the diaphragm (direct stimulation of the motor points of the diaphragm or by phrenic nerve stimulation) has, in selected patients, some advantages in comparison to conventional mechanical ventilation even for long-term use [240, 241].

For lesions at $\mathrm{C} 3$ or below, the requirement for continued ventilatory support varies from case to case, and nocturnal NIV may be an option.

$S R B D$ in spinal cord injury. Prevalence of SRBD in spinal cord injury is $4-5$ times that of the general population; it is higher in tetraplegics (60-90\%) than in paraplegics (55\%) [242-244]. OSA impairs HRQoL in tetraplegic subjects as well as cognitive function [245, 246]. Additional risk factors for SRBD in tetraplegics include narrowing of the upper airways due to chirurgical proce- 
dures to stabilize the spine, hyperplasia of neck muscles, and loss of the stretching effect on upper airways due to decreased lung volumes [247, 248].

CPAP is the treatment of choice for para- and tetraplegic patients with OSA and no sign of hypoventilation. In higher spinal cord injury level, low pressures often suffice. Higher pressures can lead to poor tolerance, especially in the presence of expiratory muscle weakness. In these cases, PSV therapy is an option.

Central sleep apnea syndromes, often due to medications, are not uncommon and are treated according to methods used in other patients with this disorder (CPAP, ASV, PSV).

Because chest wall compliance may decrease over time in tetraplegics and patients with high-level thoracic lesions, thus increasing work of breathing, alveolar hypoventilation may develop after the initial injury, and will appear initially during the night. Therefore, in the longterm follow-up of patients with high-level spinal cord injury, the risk of nocturnal hypoventilation must be considered. If nocturnal hypoventilation (with or without daytime hypoventilation) is confirmed, NIV is indicated usually with PSV devices in both PSV and PCV modes.

In the presence of SRBD and suspicion of nocturnal hypoventilation, which are often combined, further workup should include a polygraphic study which is easier to undertake than a PSG in a sleep laboratory (sleep labs are seldom equipped and trained for spinal cord injury patients), combined with continuous $\mathrm{PtcCO}_{2}$ recording [249].

Specific aspects related to NIV in spinal cord injury. NIV in high-level tetraplegia is generally possible if used during the night and partially during the day. However, 24-h non-invasive ventilation in tetraplegics is rare.

PCV and PSV modes are both used during the night. There are no studies comparing PSV to PCV modes in this population. Patient acceptance may be better with PCV modes especially in tetraplegics. If PSV modes are used, a backup frequency is mandatory because of frequent central apneas. Mouthpiece ventilation on demand or nasal prongs can be used during mobilization on a wheelchair.

Careful choice of masks, and appropriate setting of alarms are crucial, together with a specific training of all caregivers. Safety of patients with limited or no capacity to handle their mask by themselves in routine or in an emergency must be anticipated. Therefore, hospitalizations are usually required to initiate NIV.

Importantly, pressure support requirements may change over time due to changes in chest mechanics: pa- tients with a rather recent spinal cord injury often need lower pressures than patients with a stiffened thoracic cage years after the initial lesion.

In all patients with spinal cord injury and ventilatory support, a regular follow-up is required, initially at 3- to 6-month intervals, and subsequently once or twice a year.

As in all ventilator-dependent patients, a second device is always necessary if daily requirement for ventilatory support is $\geq 16 \mathrm{~h}$. This is also the case if the patient needs a ventilatory support during daytime while using an electric wheelchair, to enhance mobility and autonomy. Indeed, ventilator settings in a sitting position may differ from those used supine, and repeated dismantling and reinstalling of ventilators on a wheelchair may cause a safety problem. In this case, a built-in battery with a sufficient autonomy is necessary ("life support device") and a supplementary battery may be required.

\subsubsection{Management of Airway Secretions and Use of}

MIE (see also section 5.5)

The success of any ventilatory support for all para- and tetraplegic patients depends on efficient coughing. Two components are important: (1) to reach a maximal inspiratory capacity before coughing, and (2) to maximize peak cough flow. The first target can be reached by techniques such as continuous training of the remaining inspiratory muscles, air stacking, glossopharyngeal breathing, insufflation with a resuscitation bag, or use of a MIE device (or NIV if a MIE mode is available) [250]. The second goal can be reached by self-assisted cough techniques while supine or sitting in a wheelchair, assisted cough techniques administered by caregivers, or with MIE. A target peak cough flow of $>270 \mathrm{~L} / \mathrm{min}$ should be reached for cough to be efficient.

\section{Transition between Acute Care and Home (or Long-Term Institution)}

Success of long-term home NIV (or NIV in a heath care institution) depends on appropriate preparation and timing of the transition, anticipation of present and future requirements in terms of environment and training of caregivers, and anticipation of disease progression. Providing appropriate psychological, social, and financial support for the family and caregivers is also of major importance.

A multidisciplinary assessment and preparation of the transition to home care is necessary to include all the possible aspects of patient management in his/her new envi- 
Table 6. Goals for transition from hospital to home care (or institution)

- Ventilator settings must provide the best possible control of alveolar hypoventilation (monitored by $\mathrm{PtcCO}_{2}$ and/or ABG)

- Patient is stabilized, and comfortable with his/her home ventilator

- The patient or his/her caregivers are autonomous in putting on and taking off the mask and in maintenance of the equipment (cleaning, use of the humidifier, etc.)

- Necessary home care is organized (intervention of nurses, other healthcare workers [HCWs], chest therapists, physical therapists, technical control of ventilator and other devices)

- Home caregivers have been trained for all technical tasks, and written support is provided

- Professional support can be reached $24 \mathrm{~h} /$ day and 7 days/ week to provide appropriate guidance

- When required, backup equipment is immediately available on site

- Financial aspects are covered, and patient and/or his/her family are not exposed to a burden they cannot face

Home healthcare providers must ensure that:

- they have been extensively informed of all relevant items regarding patient and treatment before he/she is transferred

- all caregivers (GP, pulmonologist, chest therapist, etc..) are identified, and that all necessary contact information is in their possession

- they have enough qualified/trained HCWs to provide a high level of care with substitutes in case of leave absences, sickness leaves, etc.

- they offer a hotline for technical support 24/24 h 7/7 days

- they will provide regular feedback to the pulmonologist in charge, as well as results of tests agreed upon with the treating pulmonologist (i.e., pulse oximetry, data from ventilator software, transcutaneous capnography, etc.)

- HCWs within the Health Care Provider organization receive regular and structured training in the field of management of chronic respiratory failure

ronment. Practical teaching should be started early and performed throughout the hospital stay for caregivers and level of competence and understanding should be regularly assessed by the hospital team. A checklist may be useful to ensure coverage of all necessary tasks to be performed at home.

As previously mentioned, for invasive ventilation, in neighboring countries, short certifying training sessions are organized covering all aspects of respiratory care. Availability of this type of training should be encouraged in Switzerland for patients on invasive ventilation and/or for severely dependent patients.

When a transfer is planned to another long-term medical institution, training of the healthcare workers of this institution must be initiated as early as possible. Contacts must be encouraged to create bonds between the patient and his/her future caregivers. This is also important to decrease the level of stress and anxiety of the patient, his/ her close relatives, and among healthcare workers. Finally, time is needed to ensure acquisition of the necessary competences.

Evaluating the adequacy and ergonomics of the home environment, and, if necessary, performing the required changes, must be organized with the social workers, ergotherapists and physical therapists/physiotherapists.

Goals for transition to home care are summarized in Table 6.

\section{Acknowledgments}

The authors wish to express their gratitude to Patrick Pasquina (HUG, Geneva) and Dre Annemarie Hübers, P.D. (Division of Neurology, HUG, Geneva) for their contribution to the manuscript.

\section{Conflict of Interest Statement}

J.-P.J., F.M., E.I.S., M.P., K.E.B., D.A., A.-K.B., A.G., W.K., A.O., S.O., J.R., O.D.S., M.S. W.S., C.U., and G.G. have no conflict of interest regarding the manuscript.

\section{Author Contributions}

J.-P.J., F.M., E.I.S., M.P., K.B., D.A., A.-K.B., A.G., W.K., A.O., S.O., J.R., O.D.S., M.S., W.S., C.U., G.G. have provided substantial contributions to the conception or design of the work and/or or the acquisition, analysis, or interpretation of data for the work and contributed to drafting the work and/or revising it critically for important intellectual content and have given final approval of the version to be published and agree to be accountable for all aspects of the work in ensuring that questions related to the accuracy or integrity of any part of the work are appropriately investigated and resolved.

References

1 Sullivan CE, Issa FG, Berthon-Jones M, Eves L. Reversal of obstructive sleep apnoea by continuous positive airway pressure applied through the nares. Lancet. 1981 Apr;1(8225): $862-5$.

2 Chevrolet JC, Fitting JW, Knoblauch A, Domenighetti G. [Home mechanical ventilation in Switzerland in 1990. Future developments]. Schweiz Med Wochenschr. 1991 Mar; 121(11):368-77. 
3 Janssens JP, Derivaz S, Breitenstein E, De Muralt B, Fitting JW, Chevrolet JC, et al. Changing patterns in long-term noninvasive ventilation: a 7-year prospective study in the Geneva Lake area. Chest. 2003 Jan;123(1):67-79.

4 Cantero C, Adler D, Pasquina P, Uldry C, Egger $\mathrm{B}$, Prella $\mathrm{M}$, et al. Long-term noninvasive ventilation in the Geneva Lake area: indications, prevalence and modalities. Chest. 2020 Jul;158(1):279-91.

5 Cantero C, Adler D, Pasquina P, Uldry C, Egger B, Prella M, et al. Adaptive servo-ventilation: a comprehensive descriptive study in the Geneva Lake area. Front Med (Lausanne). 2020 Apr 3;7:105.

6 Kotanen P, Hanna-Riikka K, Kainu A, Brander P. The prevalence of chronic respiratory failure treated with home mechanical ventilation in Helsinki, Finland. European Respiratory Society Congress; 2019; Madrid. https:// doi.org/10.1183/13993003.congress-2019. PA2311.

7 Solèr M. Ventilation mécanique à domicile. Directives du Groupe de travail «Ventilation à domicile» de la Société suisse de pneumologie. Forum Med Suisse. 2010;10(25):445-7.

8 (SSP) Groupe de travail «Ventilation à domicile» de la Société suisse de pneumologie. Recommandations pour la ventilation mécanique à domicile. Forum Med Suisse. 2006;6: 674-8.

9 (SSP) Groupe de travail «Ventilation à domicile» de la Société suisse de pneumologie. Richtlinien für die mechanische Heimventilation vom 30. Mai 1996. Schweiz Med Wochenschr. 1996;126:2191-6.

10 Windisch W, Geiseler J, Simon K, Walterspacher S, Dreher M; on behalf of the Guideline Commission. German National Guideline for Treating Chronic Respiratory Failure with Invasive and Non-Invasive Ventilation: Revised Edition 2017 - Part 1. Respiration. 2018;96(1):66-97.

11 Windisch W, Geiseler J, Simon K, Walterspacher S, Dreher M; on behalf of the Guideline Commission. German National Guideline for Treating Chronic Respiratory Failure with Invasive and Non-Invasive Ventilation - Revised Edition 2017: Part 2. Respiration. 2018;96(2):171-203.

12 Windisch W, Walterspacher S, Siemon K, Geiseler J, Sitter H; German Society for Pneumology; Published by the German Society for Pneumology (DGP). Guidelines for non-invasive and invasive mechanical ventilation for treatment of chronic respiratory failure. Pneumologie. 2010 Oct;64(10):640-52.

13 McKim DA, Road J, Avendano M, Abdool S, Cote F, Duguid N, et al.; Canadian Thoracic Society Home Mechanical Ventilation Committee. Home mechanical ventilation: a $\mathrm{Ca}$ nadian Thoracic Society clinical practice guideline. Can Respir J. 2011 Jul-Aug; 18(4): 197-215.
14 Rabec C, Cuvelier A, Cheval C, Jaffre S, Janssens JP, Mercy M, et al. Noninvasive ventilation. The 2015 guidelines from the Groupe Assistance Ventilatoire (GAV) of the Societe de Pneumologie de Langue Francaise (SPLF). Rev Mal Respir. 2016 Dec;33(10):905-910.

15 Goldberg A. Clinical indications for noninvasive positive pressure ventilation in chronic respiratory failure due to restrictive lung disease, COPD, and nocturnal hypoventilation-a consensus conference report. Chest. 1999 Aug;116(2):521-34.

16 Adler D, Janssens JP. The Pathophysiology of Respiratory Failure: Control of Breathing, Respiratory Load, and Muscle Capacity. Respiration. 2019;97(2):93-104.

17 Tissot A, Jaffre S, Gagnadoux F, Levaillant M, Corne F, Chollet S, et al.; IRSR NIV cohort group. Home Non-Invasive Ventilation Fails to Improve Quality of Life in the Elderly: Results from a Multicenter Cohort Study. PLoS One. 2015 Oct;10(10):e0141156.

18 Carlucci A, Vitacca M, Malovini A, Pierucci P, Guerrieri A, Barbano L, et al. End-of-Life Discussion, Patient Understanding and Determinants of Preferences in Very Severe COPD Patients: A Multicentric Study. COPD. 2016 Oct;13(5):632-8.

19 Véron C, Pautex S, Weber C, Janssens JP, Cedraschi C. Recollection of participating in a trial: A qualitative study of patients with severe and very severe chronic obstructive pulmonary disease. PLoS One. 2018 Sep; 13(9):e0204701.

20 Andersen PM, Abrahams S, Borasio GD, de Carvalho M, Chio A, Van Damme P, et al.; EFNS Task Force on Diagnosis and Management of Amyotrophic Lateral Sclerosis. EFNS guidelines on the clinical management of amyotrophic lateral sclerosis (MALS)-revised report of an EFNS task force. Eur J Neurol. 2012 Mar;19(3):360-75.

21 Brown RH, Al-Chalabi A. Amyotrophic Lateral Sclerosis. N Engl J Med. 2017 Jul;377(2): $162-72$.

22 Govaarts R, Beeldman E, Kampelmacher MJ, van Tol MJ, van den Berg LH, van der Kooi AJ, et al. The frontotemporal syndrome of ALS is associated with poor survival. J Neurol. 2016 Dec;263(12):2476-83.

23 Schwarz EI, Bloch KE. Frontiers in Clinical Practice of Long-Term Care of Chronic Ventilatory Failure. Respiration. 2019;98(1):1-15.

24 Pasquina P, Adler D, Farr P, Bourqui P, Bridevaux PO, Janssens JP. What does builtin software of home ventilators tell us? An observational study of 150 patients on home ventilation. Respiration. 2012;83(4):293-9.

25 Schellhas V, Glatz C, Beecken I, Okegwo A, Heidbreder A, Young P, et al. Upper airway obstruction induced by non-invasive ventilation using an oronasal interface. Sleep Breath. 2018 Sep;22(3):781-8.
26 Haziot N, Ibrahim M, Zhu K, Thevenin CP, Hardy S, Gonzalez-Bermejo J. Impact of leaks and ventilation parameters on the efficacy of humidifiers during home ventilation for tracheostomized patients: a bench study. BMC Pulm Med. 2019 Feb;19(1):43.

27 Gregoretti C, Navalesi P, Ghannadian S, Carlucci A, Pelosi P. Choosing a ventilator for home mechanical ventilation. Breathe (Sheff). 2013;9(5):394-408

28 McArdle N, Rea C, King S, Maddison K, Ramanan D, Ketheeswaran S, et al. Treating Chronic Hypoventilation With Automatic Adjustable Versus Fixed EPAP Intelligent Volume-Assured Positive Airway Pressure Support (iVAPS): A Randomized Controlled Trial. Sleep (Basel). 2017 Oct;40(10). https:// doi.org/10.1093/sleep/zsx136.

29 Nilius G, Katamadze N, Domanski U, Schroeder M, Franke KJ. Non-invasive ventilation with intelligent volume-assured pressure support versus pressure-controlled ventilation: effects on the respiratory event rate and sleep quality in COPD with chronic hypercapnia. Int J Chron Obstruct Pulmon Dis. 2017 Mar; 12:1039-45.

30 Storre JH, Seuthe B, Fiechter R, Milioglou S, Dreher M, Sorichter S, et al. Average volumeassured pressure support in obesity hypoventilation: A randomized crossover trial. Chest. 2006 Sep;130(3):815-21.

31 Janssens JP, Metzger M, Sforza E. Impact of volume targeting on efficacy of bi-level noninvasive ventilation and sleep in obesity-hypoventilation. Respir Med. 2009 Feb;103(2): 165-72.

32 Murphy PB, Arbane G, Ramsay M, Suh ES, Mandal S, Jayaram D, et al. Safety and efficacy of auto-titrating noninvasive ventilation in COPD and obstructive sleep apnoea overlap syndrome. Eur Respir J. 2015 Aug;46(2):54851.

33 Murphy PB, Davidson C, Hind MD, Simonds A, Williams AJ, Hopkinson NS, et al. Volume targeted versus pressure support non-invasive ventilation in patients with super obesity and chronic respiratory failure: a randomised controlled trial. Thorax. 2012 Aug;67(8):72734.

34 Windisch W, Storre JH. Target volume settings for home mechanical ventilation: great progress or just a gadget? Thorax. 2012 Aug; 67(8):663-5.

35 Ekkernkamp E, Storre JH, Windisch W, Dreher M. Impact of intelligent volume-assured pressure support on sleep quality in stable hypercapnic chronic obstructive pulmonary disease patients: a randomized, crossover study. Respiration. 2014;88(4):270-6.

36 Orr JE, Coleman J, Criner GJ, Sundar KM, Tsai SC, Benjafield AV, et al. Automatic EPAP intelligent volume-assured pressure support is effective in patients with chronic respiratory failure: A randomized trial. Respirology. 2019 Dec;24(12):1204-11. 
37 Kelly JL, Jaye J, Pickersgill RE, Chatwin M, Morrell MJ, Simonds AK. Randomized trial of 'intelligent' autotitrating ventilation versus standard pressure support non-invasive ventilation: impact on adherence and physiological outcomes. Respirology. 2014 May;19(4): 596-603.

38 Jaye J, Chatwin M, Dayer M, Morrell MJ, Simonds AK. Autotitrating versus standard noninvasive ventilation: a randomised crossover trial. Eur Respir J. 2009 Mar;33(3):56671.

39 Piesiak P, Brzecka A, Kosacka M, Jankowska R. Efficacy of noninvasive volume targeted ventilation in patients with chronic respiratory failure due to kyphoscoliosis. Adv Exp Med Biol. 2015;838:53-8.

40 Patout M, Gagnadoux F, Rabec C, Trzepizur W, Georges M, Perrin C, et al. AVAPS-AE versus ST mode: A randomized controlled trial in patients with obesity hypoventilation syndrome. Respirology. 2020 Feb;resp.13784.

41 Gonzalez-Bermejo J, Rabec C, Perrin C, Langevin B, Pepin JL, Rodenstein D, et al.; SomnoNIV group. Treatment failure due to use of a 'ramp' option on pressure support home ventilators. Thorax. 2016 Aug;71(8):764-6.

42 Adler D, Perrig S, Takahashi H, Espa F, Rodenstein D, Pépin JL, et al. Polysomnography in stable COPD under non-invasive ventilation to reduce patient-ventilator asynchrony and morning breathlessness. Sleep Breath. 2012 Dec;16(4):1081-90.

43 Bonmarchand G, Chevron V, Ménard JF, Girault $\mathrm{C}$, Moritz-Berthelot $\mathrm{F}$, Pasquis $\mathrm{P}$, et al. Effects of pressure ramp slope values on the work of breathing during pressure support ventilation in restrictive patients. Crit Care Med. 1999 Apr;27(4):715-22.

44 Gonzalez-Bermejo J, Janssens JP, Rabec C, Perrin C, Lofaso F, Langevin B, et al.; SomnoNIV group. Framework for patient-ventilator asynchrony during long-term non-invasive ventilation. Thorax. 2019 Jul;74(7):7157

45 Tobin MJ, Jubran A, Laghi F. Patient-ventilator interaction. Am J Respir Crit Care Med. 2001 Apr;163(5):1059-63.

46 Tassaux D, Gainnier M, Battisti A, Jolliet P. Impact of expiratory trigger setting on delayed cycling and inspiratory muscle workload. Am J Respir Crit Care Med. 2005 Nov; 172(10):1283-9.

47 Battisti A, Tassaux D, Janssens JP, Michotte JB, Jaber S, Jolliet P. Performance characteristics of 10 home mechanical ventilators in pressure-support mode: a comparative bench study. Chest. 2005 May;127(5):1784-92.

48 Gonzalez-Bermejo J, Rabec C, Janssens JP, Perrin C, Langevin B, Pepin JL, et al. Noninvasive ventilation inefficacy due to technically incompatible ventilator settings. Intensive Care Med. 2013 Jun;39(6):1154-6.

49 Tuggey JM, Delmastro M, Elliott MW. The effect of mouth leak and humidification during nasal non-invasive ventilation. Respir Med. 2007 Sep;101(9):1874-9.
50 Nava S, Cirio S, Fanfulla F, Carlucci A, Navarra A, Negri A, et al. Comparison of two humidification systems for long-term noninvasive mechanical ventilation. Eur Respir J. 2008 Aug;32(2):460-4.

51 Rabec C, Rodenstein D, Leger P, Rouault S, Perrin C, Gonzalez-Bermejo J; SomnoNIV group. Ventilator modes and settings during non-invasive ventilation: effects on respiratory events and implications for their identification. Thorax. 2011 Feb;66(2):170-8.

52 Luján M, Sogo A, Pomares X, Monsó E, Sales B, Blanch L. Effect of leak and breathing pattern on the accuracy of tidal volume estimation by commercial home ventilators: a bench study. Respir Care. 2013 May;58(5):770-7.

53 Contal O, Vignaux L, Combescure C, Pepin JL, Jolliet P, Janssens JP. Monitoring of noninvasive ventilation by built-in software of home bilevel ventilators: a bench study. Chest. 2012 Feb;141(2):469-76.

54 Borel JC, Palot A, Patout M. Technological advances in home non-invasive ventilation monitoring: reliability of data and effect on patient outcomes. Respirology. 2019 Dec; 24(12):1143-51.

55 Pinto T, Chatwin M, Banfi P, Winck JC, Nicolini A. Mouthpiece ventilation and complementary techniques in patients with neuromuscular disease: A brief clinical review and update. Chron Respir Dis. 2017 May; 14(2): 187-93.

56 Ogna A, Lofaso F. Mouthpiece ventilation: in dividualized patient care is the key to success. Chron Respir Dis. 2016 Nov;13(4):385-6.

57 Ogna A, Prigent H, Falaize L, Leroux K, Santos D, Vaugier I, et al. Bench evaluation of commercially available and newly developed interfaces for mouthpiece ventilation. Clin Respir J. 2018 Mar;12(3):890-4.

58 Schwartz AR, Kacmarek RM, Hess DR. Factors affecting oxygen delivery with bi-level positive airway pressure. Respir Care. 2004 Mar;49(3):270-5.

59 Velasco J, Berlinski A. Albuterol Delivery Efficiency in a Pediatric Model of Noninvasive Ventilation With Double-Limb Circuit. Respir Care. 2018 Feb;63(2):141-6.

60 Berlinski A, Velasco J. Albuterol Delivery Efficiency in a Pediatric Model of Noninvasive Ventilation With a Single-Limb Circuit. Respir Care. 2019 Nov;64(11):1366-70.

61 Callegari J, Magnet FS, Taubner S, Berger M, Schwarz SB, Windisch W, et al. Interfaces and ventilator settings for long-term noninvasive ventilation in COPD patients. Int J Chron Obstruct Pulmon Dis. 2017 Jun;12:1883-9.

62 Storre JH, Callegari J, Magnet FS, Schwarz SB, Duiverman ML, Wijkstra PJ, et al. Home noninvasive ventilatory support for patients with chronic obstructive pulmonary disease: patient selection and perspectives. Int J Chron Obstruct Pulmon Dis. 2018 Feb;13:753-60.
63 Masa JF, Corral J, Alonso ML, Ordax E, Troncoso MF, Gonzalez M, et al.; Spanish Sleep Network. Efficacy of Different Treatment Alternatives for Obesity Hypoventilation Syndrome. Pickwick Study. Am J Respir Crit Care Med. 2015 Jul;192(1):86-95.

64 Duiverman ML, Vonk JM, Bladder G, van Melle JP, Nieuwenhuis J, Hazenberg A, et al. Home initiation of chronic non-invasive ventilation in COPD patients with chronic hypercapnic respiratory failure: a randomised controlled trial. Thorax. 2020 Mar;75(3):244-252.

65 Hazenberg A, Kerstjens HA, Prins SC, Vermeulen KM, Wijkstra PJ. Initiation of home mechanical ventilation at home: a randomised controlled trial of efficacy, feasibility and costs. Respir Med. 2014 Sep;108(9):1387-95.

66 Janssens JP, Borel JC, Pépin JL; SomnoNIV Group. Nocturnal monitoring of home noninvasive ventilation: the contribution of simple tools such as pulse oximetry, capnography, built-in ventilator software and autonomic markers of sleep fragmentation. Thorax. 2011 May;66(5):438-45.

67 Aarrestad S, Tollefsen E, Kleiven AL, Qvarfort M, Janssens JP, Skjønsberg OH. Validity of transcutaneous $\mathrm{PCO} 2$ in monitoring chronic hypoventilation treated with non-invasive ventilation. Respir Med. 2016 Mar;112:112-8.

68 Georges M, Nguyen-Baranoff D, Griffon L, Foignot C, Bonniaud P, Camus P, et al. Usefulness of transcutaneous $\mathrm{PCO} 2$ to assess nocturnal hypoventilation in restrictive lung disorders. Respirology. 2016 Oct;21(7):1300-6.

69 Ekkernkamp E, Welte L, Schmoor C, Huttmann SE, Dreher M, Windisch W, et al. Spot check analysis of gas exchange: invasive versus noninvasive methods. Respiration. 2015; 89(4):294-303.

70 Zavorsky GS, Cao J, Mayo NE, Gabbay R, Murias JM. Arterial versus capillary blood gases: a meta-analysis. Respir Physiol Neurobiol. 2007 Mar;155(3):268-79.

71 Magnet FS, Majorski DS, Callegari J, Schwarz SB, Schmoor C, Windisch W, et al. Capillary $\mathrm{PO} 2$ does not adequately reflect arterial $\mathrm{PO} 2$ in hypoxemic COPD patients. Int J Chron Obstruct Pulmon Dis. 2017 Sep;12:2647-53.

72 Mollard P, Bourdillon N, Letournel M, Herman $\mathrm{H}$, Gibert S, Pichon A, et al. Validity of arterialized earlobe blood gases at rest and exercise in normoxia and hypoxia. Respir Physiol Neurobiol. 2010 Jul;172(3):179-83.

73 Sauty A, Uldry C, Debétaz LF, Leuenberger P, Fitting JW. Differences in $\mathrm{PO} 2$ and $\mathrm{PCO} 2$ between arterial and arterialized earlobe samples. Eur Respir J. 1996 Feb;9(2):186-9.

74 Nassar BS, Schmidt GA. Estimating Arterial Partial Pressure of Carbon Dioxide in Ventilated Patients: How Valid Are Surrogate Measures? Ann Am Thorac Soc. 2017 Jun;14(6): 1005-14.

75 Janssens JP, Perrin E, Bennani I, de Muralt B, Titelion V, Picaud C. Is continuous transcutaneous monitoring of $\mathrm{PCO} 2$ (TcPCO2) over $8 \mathrm{~h}$ reliable in adults? Respir Med. 2001 May; 95(5):331-5.
Long-Term Mechanical Ventilation: Recommendations of the SSP
Respiration 2020;99:867-902 DOI: $10.1159 / 000510086$ 
76 Janssens JP, Howarth-Frey C, Chevrolet JC, Abajo B, Rochat T. Transcutaneous $\mathrm{PCO} 2$ to monitor noninvasive mechanical ventilation in adults: assessment of a new transcutaneous PCO2 device. Chest. 1998 Mar;113(3):76873.

77 Berry RB, Budhiraja R, Gottlieb DJ, Gozal D, Iber C, Kapur VK, et al.; American Academy of Sleep Medicine; Deliberations of the Sleep Apnea Definitions Task Force of the American Academy of Sleep Medicine. Rules for scoring respiratory events in sleep: update of the 2007 AASM Manual for the Scoring of Sleep and Associated Events. J Clin Sleep Med. 2012 Oct;8(5):597-619.

78 Ogna A, Quera Salva MA, Prigent H, Mroue G, Vaugier I, Annane D, et al. Nocturnal hypoventilation in neuromuscular disease: prevalence according to different definitions issued from the literature. Sleep Breath. 2016 May;20(2):575-81.

79 Aarrestad S, Qvarfort M, Kleiven AL, Tollefsen E, Skjønsberg OH, Janssens JP. Diagnostic accuracy of simple tools in monitoring patients with chronic hypoventilation treated with non-invasive ventilation; a prospective cross-sectional study. Respir Med. 2018 Nov; 144:30-5.

80 Dupuis-Lozeron E, Gex G, Pasquina P, Bridevaux PO, Borel JC, Soccal PM, et al. Development and validation of a simple tool for the assessment of home noninvasive ventilation: the S3-NIV questionnaire. Eur Respir J. 2018 Nov;52(5): 1801182.

81 Crimi C, Noto A, Princi P, Cuvelier A, Masa JF, Simonds A, et al. Domiciliary Non-invasive Ventilation in COPD: An International Survey of Indications and Practices. COPD. 2016 Aug;13(4):483-90.

82 Lloyd-Owen SJ, Donaldson GC, Ambrosino N, Escarabill J, Farre R, Fauroux B, et al. Patterns of home mechanical ventilation use in Europe: results from the Eurovent survey. Eur Respir J. 2005 Jun;25(6):1025-31.

83 Adler D, Pépin JL, Dupuis-Lozeron E, EspaCervena K, Merlet-Violet R, Muller H, et al. Comorbidities and Subgroups of Patients Surviving Severe Acute Hypercapnic Respiratory Failure in the Intensive Care Unit. Am J Respir Crit Care Med. 2017 Jul;196(2):200-7.

84 Dreher M, Storre JH, Schmoor C, Windisch W. High-intensity versus low-intensity noninvasive ventilation in patients with stable hypercapnic COPD: a randomised crossover trial. Thorax. 2010 Apr;65(4):303-8.

85 Windisch W, Haenel M, Storre JH, Dreher M. High-intensity non-invasive positive pressure ventilation for stable hypercapnic COPD. Int J Med Sci. 2009;6(2):72-6.

86 Murphy PB, Brignall K, Moxham J, Polkey MI, Davidson AC, Hart N. High pressure versus high intensity noninvasive ventilation in stable hypercapnic chronic obstructive pulmonary disease: a randomized crossover trial. Int J Chron Obstruct Pulmon Dis. 2012;7: 811-8.
87 Dreher M, Ekkernkamp E, Walterspacher S, Walker D, Schmoor C, Storre JH, et al. Noninvasive ventilation in COPD: impact of inspiratory pressure levels on sleep quality. Chest. 2011 Oct;140(4):939-45.

88 Lukácsovits J, Carlucci A, Hill N, Ceriana P, Pisani L, Schreiber A, et al. Physiological changes during low- and high-intensity noninvasive ventilation. Eur Respir J. 2012 Apr; 39(4):869-75.

89 Lukácsovits J, Nava S. Inspiratory pressure during noninvasive ventilation in stable COPD: help the lungs, but do not forget the heart. Eur Respir J. 2013 Mar;41(3):765-6.

90 Duiverman ML, Arellano-Maric MP, Windisch W. Long-term noninvasive ventilation in patients with chronic hypercapnic respiratory failure: assisting the diaphragm, but threatening the heart? Curr Opin Pulm Med. 2016 Mar;22(2):130-7.

91 Casanova C, Celli BR, Tost L, Soriano E, Abreu J, Velasco V, et al. Long-term controlled trial of nocturnal nasal positive pressure ventilation in patients with severe COPD. Chest. 2000 Dec;118(6):1582-90.

92 Clini E, Sturani C, Rossi A, Viaggi S, Corrado A, Donner CF, et al.; Rehabilitation and Chronic Care Study Group, Italian Association of Hospital Pulmonologists (AIPO). The Italian multicentre study on noninvasive ventilation in chronic obstructive pulmonary disease patients. Eur Respir J. 2002 Sep;20(3): 529-38.

93 McEvoy RD, Pierce RJ, Hillman D, Esterman A, Ellis EE, Catcheside PG, et al.; Australian trial of non-invasive Ventilation in Chronic Airflow Limitation (AVCAL) Study Group. Nocturnal non-invasive nasal ventilation in stable hypercapnic COPD: a randomised controlled trial. Thorax. 2009 Jul;64(7):561-6.

94 Struik FM, Lacasse Y, Goldstein RS, Kerstjens HA, Wijkstra PJ. Nocturnal noninvasive positive pressure ventilation in stable COPD: a systematic review and individual patient data meta-analysis. Respir Med. 2014 Feb;108(2): 329-37.

95 Duiverman ML, Windisch W, Storre JH, Wijkstra PJ. The role of NIV in chronic hypercapnic COPD following an acute exacerbation: the importance of patient selection? Ther Adv Respir Dis. 2016 Apr;10(2):149-57.

96 Köhnlein T, Windisch W, Köhler D, Drabik A, Geiseler J, Hartl S, et al. Non-invasive positive pressure ventilation for the treatment of severe stable chronic obstructive pulmonary disease: a prospective, multicentre, randomised, controlled clinical trial. Lancet Respir Med. 2014 Sep;2(9):698-705.

97 Struik FM, Sprooten RT, Kerstjens HA, Bladder G, Zijnen M, Asin J, et al. Nocturnal noninvasive ventilation in COPD patients with prolonged hypercapnia after ventilatory support for acute respiratory failure: a randomised, controlled, parallel-group study. Thorax. 2014 Sep;69(9):826-34.
98 Ergan B, Oczkowski S, Rochwerg B, Carlucci A, Chatwin M, Clini E, et al. European Respiratory Society guidelines on long-term home non-invasive ventilation for management of COPD. Eur Respir J. 2019 Sep 28; 54(3): 1901003

99 Murphy PB, Rehal S, Arbane G, Bourke S, Calverley PM, Crook AM, et al. Effect of Home Noninvasive Ventilation With Oxygen Therapy vs Oxygen Therapy Alone on Hospital Readmission or Death After an Acute COPD Exacerbation: A Randomized Clinical Trial. JAMA. 2017 Jun;317(21): 2177-86.

100 Carlucci A, Guerrieri A, Nava S. Palliative care in COPD patients: is it only an end-oflife issue? Eur Respir Rev. 2012 Dec;21(126): 347-54.

101 Vitacca M, Nava S, Confalonieri M, Bianchi L, Porta R, Clini E, et al. The appropriate setting of noninvasive pressure support ventilation in stable COPD patients. Chest. 2000 Nov;118(5):1286-93.

102 Dal Vecchio L, Polese G, Poggi R, Rossi A. "Intrinsic" positive end-expiratory pressure in stable patients with chronic obstructive pulmonary disease. Eur Respir J. 1990 Jan; 3(1):74-80.

103 Robert D, Gerard M, Leger L, Salamand J, Gaussorgues P, Buffat J. [Evaluation of the results of domiciliary assisted ventilation via tracheotomy]. Agressologie. 1985 Oct;26(9): 753-5.

104 Simonds AK, Elliott MW. Outcome of domiciliary nasal intermittent positive pressure ventilation in restrictive and obstructive disorders. Thorax. 1995 Jun;50(6):604-9.

105 Leger P, Bedicam JM, Cornette A, ReybetDegat O, Langevin B, Polu JM, et al. Nasal intermittent positive pressure ventilation. Long-term follow-up in patients with severe chronic respiratory insufficiency. Chest. 1994 Jan; 105(1):100-5.

106 Benhamou D, Muir JF, Raspaud C, Cuvelier A, Girault C, Portier F, et al. Long-term efficiency of home nasal mask ventilation in patients with diffuse bronchiectasis and severe chronic respiratory failure: a case-control study. Chest. 1997 Nov;112(5):1259-66.

107 Wedzicha JA, Muir JF. Noninvasive ventilation in chronic obstructive pulmonary disease, bronchiectasis and cystic fibrosis. Eur Respir J. 2002 Sep;20(3):777-84.

108 Gacouin A, Desrues B, Léna H, Quinquenel ML, Dassonville J, Delaval P. Long-term nasal intermittent positive pressure ventilation (NIPPV) in sixteen consecutive patients with bronchiectasis: a retrospective study. Eur Respir J. 1996 Jun;9(6):1246-50.

109 Bright-Thomas RJ, Johnson SC. What is the role of noninvasive ventilation in cystic fibrosis? Curr Opin Pulm Med. 2014 Nov; 20(6):618-22

110 Moran F, Bradley JM, Piper AJ. Non-invasive ventilation for cystic fibrosis. Cochrane Database Syst Rev. 2017 Feb;2:CD002769. 
111 Moran F, Bradley JM, Piper AJ. Non-invasive ventilation for cystic fibrosis. Cochrane Database Syst Rev. 2013 Apr;(4):CD002769.

112 Menadue C, Piper AJ, van 't Hul AJ, Wong KK. Non-invasive ventilation during exercise training for people with chronic obstructive pulmonary disease. Cochrane $\mathrm{Da}$ tabase Syst Rev. 2014 May;(5):CD007714.

113 Ricci C, Terzoni S, Gaeta M, Sorgente A, Destrebecq A, Gigliotti F. Physical training and noninvasive ventilation in COPD patients: a meta-analysis. Respir Care. 2014 May;59(5):709-17.

114 Camillo CA, Osadnik CR, van Remoortel H, Burtin C, Janssens W, Troosters T. Effect of "add-on" interventions on exercise training in individuals with COPD: a systematic review. ERJ Open Res. 2016 Mar;2(1):000782015.

115 Dreher M, Storre JH, Windisch W. Noninvasive ventilation during walking in patients with severe COPD: a randomised cross-over trial. Eur Respir J. 2007 May;29(5):930-6.

116 Bolton CE, Bevan-Smith EF, Blakey JD, Crowe P, Elkin SL, Garrod R, et al.; British Thoracic Society Pulmonary Rehabilitation Guideline Development Group; British Thoracic Society Standards of Care Committee. British Thoracic Society guideline on pulmonary rehabilitation in adults. Thorax. 2013 Sep;68 Suppl 2:ii1-30.

117 Duiverman ML, Wempe JB, Bladder G, Vonk JM, Zijlstra JG, Kerstjens HA, et al. Two-year home-based nocturnal noninvasive ventilation added to rehabilitation in chronic obstructive pulmonary disease patients: a randomized controlled trial. Respir Res. 2011 Aug;12(1):112.

118 Masa JF, Pépin JL, Borel JC, Mokhlesi B, Murphy PB, Sánchez-Quiroga MA. Obesity hypoventilation syndrome. Eur Respir Rev. 2019 Mar;28(151):180097.

119 Nowbar S, Burkart KM, Gonzales R, Fedorowicz A, Gozansky WS, Gaudio JC, et al. Obesity-associated hypoventilation in hospitalized patients: prevalence, effects, and outcome. Am J Med. 2004 Jan;116(1):1-7.

120 Piper AJ, Grunstein RR. Obesity hypoventilation syndrome: mechanisms and management. Am J Respir Crit Care Med. 2011 Feb; 183(3):292-8.

121 Mokhlesi B, Masa JF, Afshar M, Almadana Pacheco V, Berlowitz DJ, Borel JC, et al. The Effect of Hospital Discharge with Empiric Noninvasive Ventilation on Mortality in Hospitalized Patients with Obesity $\mathrm{Hy}$ poventilation Syndrome. An Individual $\mathrm{Pa}$ tient Data Meta-Analysis. Ann Am Thorac Soc. 2020 May;17(5):627-37.

122 Howard ME, Piper AJ, Stevens B, Holland AE, Yee BJ, Dabscheck E, et al. A randomised controlled trial of CPAP versus non-invasive ventilation for initial treatment of obesity hypoventilation syndrome. Thorax. 2017 May;72(5):437-44.
123 Piper AJ, Wang D, Yee BJ, Barnes DJ, Grunstein RR. Randomised trial of CPAP vs bilevel support in the treatment of obesity hypoventilation syndrome without severe nocturnal desaturation. Thorax. 2008 May; 63(5):395-401.

124 Masa JF, Corral J, Caballero C, Barrot E, Terán-Santos J, Alonso-Álvarez ML, et al.; Spanish Sleep Network. Non-invasive ventilation in obesity hypoventilation syndrome without severe obstructive sleep apnoea. Thorax. 2016 Oct;71(10):899-906.

125 Masa JF, Mokhlesi B, Benítez I, Gomez de Terreros FJ, Sánchez-Quiroga MA, Romero A, et al.; Spanish Sleep Network. Long-term clinical effectiveness of continuous positive airway pressure therapy versus non-invasive ventilation therapy in patients with obesity hypoventilation syndrome: a multicentre, open-label, randomised controlled trial. Lancet. 2019 Apr;393(10182):1721-32.

126 Borel JC, Tamisier R, Gonzalez-Bermejo J, Baguet JP, Monneret D, Arnol N, et al. Noninvasive ventilation in mild obesity hypoventilation syndrome: a randomized controlled trial. Chest. 2012 Mar;141(3):692702.

127 Chouri-Pontarollo N, Borel JC, Tamisier R, Wuyam B, Levy P, Pépin JL. Impaired objective daytime vigilance in obesity-hypoventilation syndrome: impact of noninvasive ventilation. Chest. 2007 Jan;131(1):148-55.

128 Mokhlesi B, Masa JF, Brozek JL, Gurubhagavatula I, Murphy PB, Piper AJ, et al. Evaluation and Management of Obesity Hypoventilation Syndrome. An Official American Thoracic Society Clinical Practice Guideline. Am J Respir Crit Care Med. 2019 Aug; 200(3):e6-24.

129 Peromaa-Haavisto P, Tuomilehto H, Kössi J Virtanen J, Luostarinen M, Pihlajamäki J, et al. Obstructive sleep apnea: the effect of bariatric surgery after 12 months. A prospective multicenter trial. Sleep Med. 2017 Jul;35:8590.

130 Sarkhosh K, Switzer NJ, El-Hadi M, Birch DW, Shi X, Karmali S. The impact of bariatric surgery on obstructive sleep apnea: a systematic review. Obes Surg. 2013 Mar;23(3): 414-23.

131 de Raaff CA, Coblijn UK, Ravesloot MJ, de Vries N, de Lange-de Klerk ES, van Wagensveld BA. Persistent moderate or severe obstructive sleep apnea after laparoscopic Roux-en-Y gastric bypass: which patients? Surg Obes Relat Dis. 2016 Dec;12(10):186672.

132 Dixon JB, Schachter LM, O’Brien PE, Jones K, Grima M, Lambert G, et al. Surgical vs conventional therapy for weight loss treatment of obstructive sleep apnea: a randomized controlled trial. JAMA. 2012 Sep; 308(11):1142-9.
133 Borel JC, Borel AL, Monneret D, Tamisier R, Levy P, Pepin JL. Obesity hypoventilation syndrome: from sleep-disordered breathing to systemic comorbidities and the need to offer combined treatment strategies. Respirology. 2012 May; 17(4):601-10.

134 Mandal S, Suh ES, Harding R, VaughanFrance A, Ramsay M, Connolly B, et al. Nutrition and Exercise Rehabilitation in Obesity hypoventilation syndrome (NERO): a pilot randomised controlled trial. Thorax. 2018 Jan;73(1):62-9.

135 Pépin JL, Borel JC, Janssens JP. Obesity hypoventilation syndrome: an underdiagnosed and undertreated condition. Am J Respir Crit Care Med. 2012 Dec;186(12): 1205-7.

136 Piper A. Obesity Hypoventilation Syndrome: Weighing in on Therapy Options. Chest. 2016 Mar; 149(3):856-68.

137 Berry RB, Chediak A, Brown LK, Finder J, Gozal D, Iber C, et al.; NPPV Titration Task Force of the American Academy of Sleep Medicine. Best clinical practices for the sleep center adjustment of noninvasive positive pressure ventilation (NPPV) in stable chronic alveolar hypoventilation syndromes. J Clin Sleep Med. 2010 Oct;6(5): 491-509.

138 Borel JC, Gonzalez-Bermejo J. Is it still relevant to consider polysomnography as essential for noninvasive ventilation titration? Eur Respir J. 2019 May;53(5):1900619.

139 Hannan LM, Rautela L, Berlowitz DJ, McDonald CF, Cori JM, Sheers N, et al. Randomised controlled trial of polysomnographic titration of noninvasive ventilation. Eur Respir J. 2019 May;53(5):1802118.

140 Fernandez Alvarez R, Rabec C, Rubinos Cuadrado G, Cascon Hernandez JA, Rodriguez $\mathrm{P}$, Georges $\mathrm{M}$, et al. Monitoring Noninvasive Ventilation in Patients with Obesity Hypoventilation Syndrome: Comparison between Ventilator Built-in Software and Respiratory Polygraphy. Respiration. 2017; 93(3):162-9.

141 Georges M, Adler D, Contal O, Espa F, Perrig S, Pépin JL, et al. Reliability of ApneaHypopnea Index Measured by a Home BiLevel Pressure Support Ventilator Versus a Polysomnographic Assessment. Respir Care. 2015 Jul;60(7):1051-6.

142 Contal O, Adler D, Borel JC, Espa F, Perrig $S$, Rodenstein $D$, et al. Impact of different backup respiratory rates on the efficacy of noninvasive positive pressure ventilation in obesity hypoventilation syndrome: a randomized trial. Chest. 2013 Jan;143(1):37-46.

143 Mokhlesi B. Obesity hypoventilation syndrome: a state-of-the-art review. Respir Care. 2010 Oct;55(10):1347-62.

144 Pankow W, Podszus T, Gutheil T, Penzel T, Peter J, Von Wichert P. Expiratory flow limitation and intrinsic positive end-expiratory pressure in obesity. J Appl Physiol (1985). 1998;85(4):1236-43.
Long-Term Mechanical Ventilation: Recommendations of the SSP
Respiration 2020;99:867-902 DOI: $10.1159 / 000510086$ 
145 Rubinstein I, Zamel N, DuBarry L, Hoffstein V. Airflow limitation in morbidly obese, nonsmoking men. Ann Intern Med. 1990 Jun;112(11):828-32.

146 Steier J, Jolley CJ, Seymour J, Roughton M, Polkey MI, Moxham J. Neural respiratory drive in obesity. Thorax. 2009 Aug;64(8): 719-25.

147 Zavorsky GS, Hoffman SL. Pulmonary gas exchange in the morbidly obese. Obes Rev. 2008 Jul;9(4):326-39.

148 Priou P, Hamel JF, Person C, Meslier N, Racineux JL, Urban T, et al. Long-term outcome of noninvasive positive pressure ventilation for obesity hypoventilation syndrome. Chest. 2010 Jul;138(1):84-90.

149 Masa JF, Corral J, Romero A, Caballero C, Terán-Santos J, Alonso-Álvarez ML, et al.; Spanish Sleep Network. The Effect of Supplemental Oxygen in Obesity Hypoventilation Syndrome. J Clin Sleep Med. 2016 Oct; 12(10):1379-88

150 de Picciotto C, Duménil C, Auzel O, Giraud V, Bonay M. Paradoxical worsening of hypoxemia in a patient treated by noninvasive positive pressure ventilation for obesity hypoventilation syndrome with concomitant obstructive sleep apnea: a case report. J Med Case Reports. 2017 Aug;11(1):234.

151 Masa JF, Mokhlesi B, Benítez I, Mogollon MV, Gomez de Terreros FJ, Sánchez-Quiroga MA, et al.; Spanish Sleep Network; LongTerm Pickwick Randomized Controlled Clinical Trial. Echocardiographic Changes with Positive Airway Pressure Therapy in Obesity Hypoventilation Syndrome. Am J Respir Crit Care Med. 2020 Mar;201(5): 586-97.

152 Vrijsen B, Buyse B, Belge C, Testelmans D. Upper airway obstruction during noninvasive ventilation induced by the use of an oronasal mask. J Clin Sleep Med. 2014 Sep; 10(9):1033-5.

153 Laaban JP, Chailleux E. Daytime hypercapnia in adult patients with obstructive sleep apnea syndrome in France, before initiating nocturnal nasal continuous positive airway pressure therapy. Chest. 2005 Mar;127(3): $710-5$.

154 Bingol Z, Pıhtılı A, Cagatay P, Okumus G, Kiyan E. Clinical predictors of obesity hypoventilation syndrome in obese subjects with obstructive sleep apnea. Respir Care. 2015 May;60(5):666-72.

155 Damiani MF, Falcone VA, Carratù $P$, Scoditti C, Bega E, Dragonieri S, et al. Using $\mathrm{PaCO} 2$ values to grade obesity-hypoventilation syndrome severity: a retrospective study. Multidiscip Respir Med. 2017 May; 12(1):14.

156 Nickol AH, Hart N, Hopkinson NS, Moxham J, Simonds A, Polkey MI. Mechanisms of improvement of respiratory failure in patients with restrictive thoracic disease treated with non-invasive ventilation. Thorax. 2005 Sep;60(9):754-60.
157 Shneerson JM, Simonds AK. Noninvasive ventilation for chest wall and neuromuscular disorders. Eur Respir J. 2002 Aug;20(2): 480-7.

158 Doménech-Clar R, Nauffal-Manzur D, Perpiñá-Tordera $\mathrm{M}, \quad$ Compte-Torrero $\mathrm{L}$, Macián-Gisbert V. Home mechanical ventilation for restrictive thoracic diseases: effects on patient quality-of-life and hospitalizations. Respir Med. 2003 Dec;97(12):1320-7.

159 Ferris G, Servera-Pieras E, Vergara P, Tzeng AC, Perez M, Marin J, et al. Kyphoscoliosis ventilatory insufficiency: noninvasive management outcomes. Am J Phys Med Rehabil. 2000 Jan-Feb;79(1):24-9.

160 Gonzalez C, Ferris G, Diaz J, Fontana I, Nuñez J, Marín J. Kyphoscoliotic ventilatory insufficiency: effects of long-term intermittent positive-pressure ventilation. Chest. 2003 Sep;124(3):857-62.

161 Grassi V, Tantucci C. Respiratory prognosis in chest wall diseases. Monaldi Arch Chest Dis. 1993;48(2): 183-7.

162 Masa JF, Celli BR, Riesco JA, Sánchez de Cos J, Disdier C, Sojo A. Noninvasive positive pressure ventilation and not oxygen may prevent overt ventilatory failure in patients with chest wall diseases. Chest. 1997 Jul; 112(1):207-13.

163 Schönhofer B, Barchfeld T, Wenzel M, Köhler D. Long term effects of non-invasive mechanical ventilation on pulmonary haemodynamics in patients with chronic respiratory failure. Thorax. 2001 Jul;56(7):524-8.

164 Schonhofer B, Wallstein S, Wiese C, Kohler D. Noninvasive mechanical ventilation improves endurance performance in patients with chronic respiratory failure due to thoracic restriction. Chest. 2001 May;119(5): 1371-8.

165 Simonds AK. Nasal intermittent positive pressure ventilation in neuromuscular and chest wall disease. Monaldi Arch Chest Dis. 1993;48(2):165-8.

166 Ward S, Chatwin M, Heather S, Simonds AK. Randomised controlled trial of non-invasive ventilation (NIV) for nocturnal hypoventilation in neuromuscular and chest wall disease patients with daytime normocapnia. Thorax. 2005 Dec;60(12):1019-24.

167 Zaccaria S, Zaccaria E, Zanaboni S, Patessio A, Braghiroli A, Spada EL, et al. Home mechanical ventilation in kyphoscoliosis. Monaldi Arch Chest Dis. 1993;48(2):161-4.

168 Pehrsson K, Bake B, Larsson S, Nachemson A. Lung function in adult idiopathic scoliosis: a 20 year follow up. Thorax. $1991 \mathrm{Jul}$; 46(7):474-8.

169 Chailleux E, Fauroux B, Binet F, Dautzenberg B, Polu JM. Predictors of survival in patients receiving domiciliary oxygen therapy or mechanical ventilation. A 10-year analysis of ANTADIR Observatory. Chest. 1996 Mar;109(3):741-9.
170 Gustafson T, Franklin KA, Midgren B, Pehrsson K, Ranstam J, Ström K. Survival of patients with kyphoscoliosis receiving mechanical ventilation or oxygen at home. Chest. 2006 Dec;130(6):1828-33.

171 Fuschillo S, De Felice A, Martucci M, Gaudiosi C, Pisano V, Vitale D, et al. Pulmonary rehabilitation improves exercise capacity in subjects with kyphoscoliosis and severe respiratory impairment. Respir Care. 2015 Jan;60(1):96-101.

$172 \mathrm{Ng} \mathrm{L}$, Khan F, Mathers S. Multidisciplinary care for adults with amyotrophic lateral sclerosis or motor neuron disease. Cochrane Database Syst Rev. 2009 Oct;(4):CD007425.

173 Rooney J, Byrne S, Heverin M, Tobin K, Dick A, Donaghy C, et al. A multidisciplinary clinic approach improves survival in ALS: a comparative study of ALS in Ireland and Northern Ireland. J Neurol Neurosurg Psychiatry. 2015 May;86(5):496-501.

174 Paipa AJ, Povedano M, Barcelo A, Domínguez R, Saez M, Turon J, et al. Survival benefit of multidisciplinary care in amyotrophic lateral sclerosis in Spain: association with noninvasive mechanical ventilation. J Multidiscip Healthc. 2019 Jun;12:465-70.

175 O'Brien D, Stavroulakis T, Baxter S, Norman $\mathrm{P}$, Bianchi S, Elliott M, et al. The optimisation of noninvasive ventilation in amyotrophic lateral sclerosis: a systematic review. Eur Respir J. 2019 Sep;54(3):1900261.

176 Bourke SC, Tomlinson M, Williams TL, Bullock RE, Shaw PJ, Gibson GJ. Effects of non-invasive ventilation on survival and quality of life in patients with amyotrophic lateral sclerosis: a randomised controlled trial. Lancet Neurol. 2006 Feb;5(2):140-7.

177 Kohler M, Clarenbach CF, Böni L, Brack T, Russi EW, Bloch KE. Quality of life, physical disability, and respiratory impairment in Duchenne muscular dystrophy. Am J Respir Crit Care Med. 2005 Oct;172(8):1032-6.

178 Fitting JW, Paillex R, Hirt L, Aebischer P, Schluep M. Sniff nasal pressure: a sensitive respiratory test to assess progression of amyotrophic lateral sclerosis. Ann Neurol. 1999 Dec;46(6):887-93.

179 Polkey MI, Lyall RA, Yang K, Johnson E, Leigh PN, Moxham J. Respiratory Muscle Strength as a Predictive Biomarker for Survival in Amyotrophic Lateral Sclerosis. Am J Respir Crit Care Med. 2017 Jan;195(1):8695.

180 Janssens JP, Adler D, Iancu Ferfoglia R, Poncet A, Genton Graf L, Leuchter I, et al. Assessing Inspiratory Muscle Strength for Early Detection of Respiratory Failure in Motor Neuron Disease: Should We Use MIP, SNIP, or Both? Respiration. 2019;98(2):114-24.

181 Georges M, Morélot-Panzini C, Similowski $\mathrm{T}$, Gonzalez-Bermejo J. Noninvasive ventilation reduces energy expenditure in amyotrophic lateral sclerosis. BMC Pulm Med. 2014 Feb;14(1):17. 
182 Genton L, Viatte V, Janssens JP, Héritier AC, Pichard C. Nutritional state, energy intakes and energy expenditure of amyotrophic lateral sclerosis (ALS) patients. Clin Nutr. 2011 Oct;30(5):553-9.

183 Héritier AC, Janssens JP, Adler D, Ferfoglia RI, Genton L. Should patients with ALS gain weight during their follow-up? Nutrition. 2015 Nov-Dec;31(11-12):1368-71.

184 Conde B, Martins N, Brandão M, Pimenta AC, Winck JC. Upper Airway Video Endoscopy: assessment of the response to positive pressure ventilation and mechanical in-exsufflation. Pulmonology. 2019 Sep - Oct; 25(5):299-304.

185 Toussaint M, Chatwin M, Verhulst S, Reychler G. Preference of neuromuscular patients regarding equipment for daytime mouthpiece ventilation: A randomized crossover study. Clin Respir J. 2020 Mar; 14(3):214-21.

186 Chatwin M. How to use a mechanical insufflator-exsufflator " cough assist machine ". Breathe (Sheff). 2008;4(4):321-5.

187 Gonçalves MR, Winck JC. Commentary: exploring the potential of mechanical insufflation-exsufflation. Breathe (Sheff). 2008;4(4): 326-9.

188 Bach JR, Bianchi C, Vidigal-Lopes M, Turi S, Felisari G. Lung inflation by glossopharyngeal breathing and "air stacking" in Duchenne muscular dystrophy. Am J Phys Med Rehabil. 2007 Apr;86(4):295-300.

189 Tzeng AC, Bach JR. Prevention of pulmonary morbidity for patients with neuromuscular disease. Chest. 2000 Nov;118(5):13906.

190 Chatwin M, Simonds AK. Long-Term Mechanical Insufflation-Exsufflation Cough Assistance in Neuromuscular Disease: Patterns of Use and Lessons for Application. Respir Care. 2020 Feb;65(2):135-43.

191 Andersen TM, Sandnes A, Fondenes O, Nilsen RM, Tysnes OB, Heimdal JH, et al. Laryngeal Responses to Mechanically Assisted Cough in Progressing Amyotrophic Lateral Sclerosis. Respir Care. 2018 May; 63(5):538-49.

192 Senent C, Golmard JL, Salachas F, Chiner E, Morelot-Panzini C, Meninger V, et al. A comparison of assisted cough techniques in stable patients with severe respiratory insufficiency due to amyotrophic lateral sclerosis. Amyotroph Lateral Scler. 2011 Jan;12(1): 26-32.

193 Andersen T, Sandnes A, Brekka AK, Hilland $\mathrm{M}$, Clemm H, Fondenes O, et al. Laryngeal response patterns influence the efficacy of mechanical assisted cough in amyotrophic lateral sclerosis. Thorax. 2017 Mar;72(3): 221-9.

194 Andersen TM, Sandnes A, Fondenes O, Clemm H, Halvorsen T, Nilsen RM, et al. Laryngoscopy Can Be a Valuable Tool for Unexpected Therapeutic Response in Noninvasive Respiratory Interventions. Respir Care. 2018 Nov;63(11):1459-61.
195 Malfertheiner MV, Lerzer C, Kolb L, Heider $\mathrm{K}$, Zeman F, Gfüllner F, et al. Whom are we treating with adaptive servo-ventilation? A clinical post hoc analysis. Clin Res Cardiol. 2017 Sep;106(9):702-10.

196 Jaffuel D, Philippe C, Rabec C, Mallet JP, Georges M, Redolfi S, et al. What is the remaining status of adaptive servo-ventilation? The results of a real-life multicenter study (OTRLASV-study) : adaptive servoventilation in real-life conditions. Respir Res. 2019 Oct;20(1):235.

197 Reddy R, Adamo D, Kufel T, Porhomayon J, El-Solh AA. Treatment of opioid-related central sleep apnea with positive airway pressure: a systematic review. J Opioid Manag. 2014 Jan-Feb;10(1):57-62.

198 Cowie MR, Woehrle H, Wegscheider K, Angermann C, d'Ortho MP, Erdmann E, et al. Adaptive Servo-Ventilation for Central Sleep Apnea in Systolic Heart Failure. N Engl J Med. 2015 Sep;373(12):1095-105.

199 Marrara KT, Di Lorenzo VA, Jaenisch RB, Cabiddu R, de Oliveira Sato T, Mendes RG, et al. Noninvasive Ventilation as an Important Adjunct to an Exercise Training Program in Subjects With Moderate to Severe COPD. Respir Care. 2018 Nov;63(11):138898.

200 Vitacca M, Ambrosino N. Non-Invasive Ventilation as an Adjunct to Exercise Training in Chronic Ventilatory Failure: A Narrative Review. Respiration. 2019;97(1):3-11.

201 Borel JC, Wuyam B, Chouri-Pontarollo N, Deschaux C, Levy P, Pépin JL. During exercise non-invasive ventilation in chronic restrictive respiratory failure. Respir Med. 2008 May;102(5):711-9.

202 Menadue C, Alison JA, Piper AJ, Flunt D, Ellis ER. Non-invasive ventilation during arm exercise and ground walking in patients with chronic hypercapnic respiratory failure. Respirology. 2009 Mar;14(2):251-9.

203 Menadue C, Alison JA, Piper AJ, Flunt D, Ellis ER. Bilevel ventilation during exercise in acute on chronic respiratory failure: a preliminary study. Respir Med. 2010 Feb; 104(2):219-27.

204 Dreher M, Doncheva E, Schwoerer A, Walterspacher S, Sonntag F, Kabitz HJ, et al. Preserving oxygenation during walking in severe chronic obstructive pulmonary disease: noninvasive ventilation versus oxygen therapy. Respiration. 2009;78(2):154-60.

205 van 't Hul A, Gosselink R, Hollander P, Postmus P, Kwakkel G. Training with inspiratory pressure support in patients with severe COPD. Eur Respir J. 2006 Jan;27(1):65-72.

206 Duiverman ML, Wempe JB, Bladder G, Jansen DF, Kerstjens HA, Zijlstra JG, et al. Nocturnal non-invasive ventilation in addition to rehabilitation in hypercapnic patients with COPD. Thorax. 2008 Dec;63(12): 1052-7.
207 Dreher M, Ekkernkamp E, Schmoor C, Schoenheit-Kenn U, Winterkamp S, Kenn K. Pulmonary rehabilitation and noninvasive ventilation in patients with hypercapnic interstitial lung disease. Respiration. 2015; 89(3):208-13.

208 Takahashi H, Molleyres S, Dousse N, Contal O, Janssens JP. Early exercise training after exacerbation in patients with chronic respiratory failure. Rev Med Suisse. 2011;7(318): 2301-2, 2304-6.

209 Diaz de Teran T, Barbagelata E, Cilloniz C, Nicolini A, Perazzo T, Perren A, et al. Noninvasive ventilation in palliative care: a systematic review. Minerva Med. 2019 Dec; 110(6):555-63.

210 Nava S, Ferrer M, Esquinas A, Scala R, Groff $\mathrm{P}$, Cosentini R, et al. Palliative use of noninvasive ventilation in end-of-life patients with solid tumours: a randomised feasibility trial. Lancet Oncol. 2013 Mar;14(3):219-27.

211 Rajala K, Lehto JT, Saarinen M, Sutinen E, Saarto T, Myllärniemi M. End-of-life care of patients with idiopathic pulmonary fibrosis. BMC Palliat Care. 2016 Oct;15(1):85.

212 Tripodoro VA, Rabec CA, De Vito EL. Withdrawing noninvasive ventilation at end-of-life care: is there a right time? Curr Opin Support Palliat Care. 2019 Dec;13(4): 344-50.

213 Heritier Barras AC, Adler D, Iancu Ferfoglia R, Ricou B, Gasche Y, Leuchter I, et al.; CeSLA group. Is tracheostomy still an option in amyotrophic lateral sclerosis? Reflections of a multidisciplinary work group. Swiss Med Wkly. 2013 Aug; 143:w13830.

214 Schwarz EI, Mackie M, Weston N, Tincknell L, Beghal G, Cheng MC, et al. Time-to-death in chronic respiratory failure on home mechanical ventilation: A cohort study. Respir Med. 2020 Feb;162:105877.

215 Povitz M, Rose L, Shariff SZ, Leonard S, Welk B, Jenkyn KB, et al. Home Mechanical Ventilation: A 12-Year Population-Based Retrospective Cohort Study. Respir Care. 2018 Apr;63(4):380-7.

216 McKim DA, Griller N, LeBlanc C, Woolnough A, King J. Twenty-four hour noninvasive ventilation in Duchenne muscular dystrophy: a safe alternative to tracheostomy. Can Respir J. 2013 Jan-Feb;20(1):e5-9.

217 Fayssoil A, Ogna A, Chaffaut C, Lamothe L, Ambrosi X, Nardi O, et al. Natural history of cardiac function in Duchenne and Becker muscular dystrophies on home mechanical ventilation. Medicine (Baltimore). $2018 \mathrm{Jul}$ 97(27):e11381.

218 Bach JR, Martinez D. Duchenne muscular dystrophy: continuous noninvasive ventilatory support prolongs survival. Respir Care. 2011 Jun;56(6):744-50.

219 Bach JR. Noninvasive Respiratory Management of Patients With Neuromuscular Disease. Ann Rehabil Med. 2017 Aug;41(4): 519-38.
Long-Term Mechanical Ventilation: Recommendations of the SSP
Respiration 2020;99:867-902 DOI: $10.1159 / 000510086$ 
220 Nonoyama ML, McKim DA, Road J, Guerriere $\mathrm{D}$, Coyte $\mathrm{PC}$, Wasilewski $\mathrm{M}$, et al. Healthcare utilisation and costs of home mechanical ventilation. Thorax. 2018 Jan; 73(7):thoraxjnl-2017-211138.

221 Kohler M, Clarenbach CF, Bahler C, Brack T, Russi EW, Bloch KE. Disability and survival in Duchenne muscular dystrophy. J Neurol Neurosurg Psychiatry. 2009 Mar; 80(3):320-5.

222 Markström A, Sundell K, Lysdahl M, Andersson G, Schedin U, Klang B. Quality-of-life evaluation of patients with neuromuscular and skeletal diseases treated with noninvasive and invasive home mechanical ventilation. Chest. 2002 Nov;122(5):1695-700.

223 Huttmann SE, Windisch W, Storre JH. Invasive home mechanical ventilation: living conditions and health-related quality of life. Respiration. 2015;89(4):312-21.

224 Ilan O, Gross M, Zaltzman Y, Sasson A, Marcus EL. Diagnosis and conservative management of late tracheotomy complications in chronic ventilator-dependent patients. Head Neck. 2015 May;37(5):716-21.

225 MacIntyre EJ, Asadi L, Mckim DA, Bagshaw SM. Clinical Outcomes Associated with Home Mechanical Ventilation: A Systematic Review. Can Respir J. 2016;2016:6547180.

226 Simonds AK. Home Mechanical Ventilation: an Overview. Ann Am Thorac Soc. 2016 Nov;13(11):2035-44.

227 Herer B. Outcomes of Tracheostomized Subjects Undergoing Prolonged Mechanical Ventilation in an Intermediate-Care Facility. Respir Care. 2018 Mar;63(3):282-8.

228 Marchese S, Corrado A, Scala R, Corrao S, Ambrosino N; Intensive Care Study Group, Italian Association of Hospital Pulmonologists (AIPO). Tracheostomy in patients with long-term mechanical ventilation: a survey. Respir Med. 2010 May;104(5):749-53.

229 Scanlon PD, Loring SH, Pichurko BM, McCool FD, Slutsky AS, Sarkarati M, et al. Respiratory mechanics in acute quadriplegia. Lung and chest wall compliance and dimensional changes during respiratory maneuvers. Am Rev Respir Dis. 1989 Mar;139(3): 615-20.

230 Goldman JM, Williams SJ, Denison DM. The rib cage and abdominal components of respiratory system compliance in tetraplegic patients. Eur Respir J. 1988 Mar;1(3):242-7.
231 Estenne M, De Troyer A. The effects of tetraplegia on chest wall statics. Am Rev Respir Dis. 1986 Jul;134(1):121-4.

232 Postma K, Haisma JA, de Groot S, Hopman MT, Bergen MP, Stam HJ, et al. Changes in pulmonary function during the early years after inpatient rehabilitation in persons with spinal cord injury: a prospective cohort study. Arch Phys Med Rehabil. 2013 Aug; 94(8):1540-6.

233 Mueller G, de Groot S, van der Woude L, Hopman MT. Time-courses of lung function and respiratory muscle pressure generating capacity after spinal cord injury: a prospective cohort study. J Rehabil Med. 2008 Apr;40(4):269-76.

234 Chen CF, Lien IN, Wu MC. Respiratory function in patients with spinal cord injuries: effects of posture. Paraplegia. $1990 \mathrm{Feb}$; 28(2):81-6.

235 Baydur A, Adkins RH, Milic-Emili J. Lung mechanics in individuals with spinal cord injury: effects of injury level and posture. Appl Physiol (1985). 2001;90(2):405-11.

236 Grimm DR, Chandy D, Almenoff PL, Schilero G, Lesser M. Airway hyperreactivity in subjects with tetraplegia is associated with reduced baseline airway caliber. Chest. 2000 Nov;118(5):1397-404.

237 Schilero GJ, Grimm DR, Bauman WA, Lenner R, Lesser M. Assessment of airway caliber and bronchodilator responsiveness in subjects with spinal cord injury. Chest. 2005 Jan;127(1):149-55.

238 Tran K, Hukins C, Geraghty T, Eckert B, Fraser L. Sleep-disordered breathing in spinal cord-injured patients: a short-term longitudinal study. Respirology. 2010 Feb; 15(2):272-6.

239 Stockhammer E, Tobon A, Michel F, Eser P, Scheuler W, Bauer W, et al. Characteristics of sleep apnea syndrome in tetraplegic patients. Spinal Cord. 2002 Jun;40(6):286-94.

240 Hirschfeld S, Vieweg H, Schulz AP, Thietje $\mathrm{R}$, Baer GA. Threshold currents of platinum electrodes used for functional electrical stimulation of the phrenic nerves for treatment of central apnea. Pacing Clin Electrophysiol. 2013 Jun;36(6):714-8
241 Adler D, Gonzalez-Bermejo J, Duguet A, Demoule A, Le Pimpec-Barthes F, Hurbault A, et al. Diaphragm pacing restores olfaction in tetraplegia. Eur Respir J. 2009 Aug;34(2): 365-70.

242 Berlowitz DJ, Spong J, Gordon I, Howard ME, Brown DJ. Relationships between objective sleep indices and symptoms in a community sample of people with tetraplegia. Arch Phys Med Rehabil. 2012 Jul;93(7): 1246-52.

243 Chiodo AE, Sitrin RG, Bauman KA. Sleep disordered breathing in spinal cord injury: A systematic review. J Spinal Cord Med. 2016 Jul;39(4):374-82.

244 Sankari A, Bascom AT, Chowdhuri S, Badr MS. Tetraplegia is a risk factor for central sleep apnea. J Appl Physiol (1985). 2014; 116(3):345-53.

245 Sajkov D, Marshall R, Walker P, Mykytyn I, McEvoy RD, Wale J, et al. Sleep apnoea related hypoxia is associated with cognitive disturbances in patients with tetraplegia. Spinal Cord. 1998 Apr;36(4):231-9.

246 Schembri R, Spong J, Graco M, Berlowitz DJ; COSAQ study team. Neuropsychological Function in Patients with Acute Tetraplegia and Sleep Disordered Breathing. Sleep (Basel). 2017;40(2)

247 Burns SP, Kapur V, Yin KS, Buhrer R. Factors associated with sleep apnea in men with spinal cord injury: a population-based casecontrol study. Spinal Cord. 2001 Jan;39(1): $15-22$.

248 Sankari A, Bascom A, Oomman S, Badr MS. Sleep disordered breathing in chronic spinal cord injury. J Clin Sleep Med. 2014 Jan; 10(1):65-72.

249 Adler D, Janssens JP. Estimating the probability of OSA in the spinal cord injury population: specific tools are still needed. Thorax. 2018 Sep;73(9):803-5.

250 Del Amo Castrillo L, Lacombe M, Boré A, Vaugier I, Falaize L, Orlikowski D, et al. Comparison of Two Cough-Augmentation Techniques Delivered by a Home Ventilator in Subjects With Neuromuscular Disease. Respir Care. 2019 Mar;64(3):255-61.

251 Janssens JP, Adler DE, Gonzalez-Bermejo J. Long-term NIV failure: causes and problem solving. In: Simonds AK, editor. Practical Handbook Noninvasive Ventilation. Sheffield: European Respiratory Society; 2015. p 234-45. 